\title{
El vidrio en la construcción. Situación actual y orientación de la I+D
}

\author{
Le verre dans la construction. \\ Situation actuelle et orientation de la $R+D$
}

Fecha de recepción: 31-1-91

JOSE ANTONIO COTO $\left({ }^{*}\right)$

$R E S U M E N$

El vidrio, bajo sus diferentes formas y composiciones, constituye uno de los materiales más utilizados en la construcción. Desempeña múltiples funciones: Estética, Confort, Seguridad, ... Aunque se trata de un material muy antiguo, gracias al esfuerzo de $1+D$, está teniendo una importante evolución durante estos últimos años. Se desarrollan nuevas propiedades y funciones mediante modificaciones en su composición, tratamientos de su superficie o asociación con otros productos.

Se recoge, en esta comunicación, un extenso número de nuevos productos y sus procedimientos de obtención, destacando su aplicación y funcionalidad en la construcción. Se da cierta extensión a los diferentes tratamientos de superficie (principalmente, capas delgadas) sobre vidrio plano, por su especial implantación en la construcción actual. Igualmente, se describen los productos compuestos y sus utilizaciones más funcionales.

Los vidrios con propiedades variables a voluntad son objeto de múltiples desarrollos actuales $y$, sin duda, serán de gran aplicación en la construcción en un futuro próximo.

Se termina esta comunicación con una referencia, necesariamente breve, a los vidrios estructurales y las diferentes fibras de vidrio (tanto de aislamiento térmico y acústico, como de refuerzo), también de gran interés y difusión en la construcción.

\author{
RESUME \\ Le verre, sous des formes et compositions différentes, \\ représente un matériau très utilisé dans le bâtiment. Ses \\ fonctions sont multiples: Esthétique, Confort, Sécurité, ... \\ Bien qu'il s'agit d'un matériau très ancien, grâce à \\ l'effort de $R+D$, son évolution pendant ces dernières \\ années a été très importante. On a développé de nouvelles \\ propriétés et fonctions en modifiant la composition, les \\ traitements de surface ou l'association avec d'autres \\ produits.
}

Dans cette communication on a recueilli un large nombre de nouveaux produits ainsi que ses procédés d'obtention, en soulignant son application et fonctionnalité dans le bâtiment. On a consacré une spéciale attention aux traitements de surface (principalement, couches minces) sur verre plat, d'après sa remarquable implantation dans le bâtiment actuel. De même on a détaillé les produits composés et ses utilisations plus fonctionnelles.

Les verres ayant des propriétés variables à volonté sont actuellement l'objet de multiples développements et, sans doute, ils seront appliqués davantage à l'avenir.

On conclut cette communication en faisant une brève référence aux verres structurels et aux différentes fibres de verre (d'isolation thermique et acoustique, ainsi que de renforcement) à grand intérêt aussi pour le bâtiment.

\section{INTRODUCCION}

El vidrio es un material permanentemente asociado a la historia de la humanidad. Ya el hombre prehistórico comienza a apreciar la utilidad y la belleza de aquellos vidrios naturales surgidos de las erupciones que acompañaron la formación de la corteza terrestre. Será muchos miles de años más tarde, probablemente entre los 5.000 y 10.000 años a.C., cuando el hombre comienza a producir los primeros objetos de vidrio.

\section{INTRODUCTION}

Le verre est un matériau qui a toujours été associé è l'histoire de l'humanité. Déjà l'homme préhistorique commence à apprécier l'utilité et la beauté des verres naturels jaillis des éruptions qui accompagnérent la formation de l'écorce terrestre. Des milliers d'années plus tard, probablement entre les 5.000 et 10.000 ans av. JC, l'homme commence à produire les premiers objets de verre.

(*) Director de Investigación y Desarrollo Técnico. Cristalería Española, S.A. ESPAÑA. 
El vidrio aplicado a la construcción comienza a desarrollarse durante el imperio romano. De la proliferación de hornos y artesanos vidrieros surgen las primeras aplicaciones en pavimentos, placas de recubrimiento de paredes, ... llegando pronto al cerramiento de huecos.

Una inquietud permanente del hombre ha sido su hábitat. Ha buscado siempre la forma de protegerse de la intemperie, de las agresiones del medio exterior, de la intromisión, ... pero sin resignarse a permanecer en el aislamiento, en la oscuridad, ... Ha tratado de conjugar su seguridad y protección con la utilidad de la luz, el calor, la observación del exterior, ... Surge así la aplicación más importante del vidrio en la construcción. Con sus funciones contradictorias: separa y une a la vez; es inerte y sus efectos son cambiantes; da ligereza y armonía, y es resistente; compone con la luz reflejos, y es transparente; ... facilita la gran expansión de la arquitectura como arte y técnica de la construcción.

Las primeras ventanas conocidas proceden de las ruinas de Pompeya (Siglo I de la era cristiana). Curiosamente estos vidrios, de composición próxima a los actuales y de superficies ya importantes (cercanas al $\mathrm{m}^{2}$ ), están obtenidos por una tecnología de colada y prensado que no se recuperará, de nuevo, hasta el siglo XVII. Es en 1688, cuando la manufactura real de SaintGobain (Francia), comienza a explotar y exportar un nuevo procedimiento, de colada del vidrio fundido y posterior laminación, que permite obtener vidrios planos de superficies ya importantes. Es el comienzo de la industrialización del vidrio.

La simbiosis vidrio-construcción está ya consolidada, pero es, sin duda, en los últimos años, cuando este material se integra de forma total en la arquitectura creativa, pasando de ser un elemento estético, o un material transparente de separación, a un material multifuncional. Combina perfectamente su cualidad principal, la transparencia a la luz, con acciones selectivas frente a otras radiaciones, con el aislamiento del ruido, del calor, del fuego, la resistencia al impacto o la efracción, con su comportamiento como elemento estructural, con la aportación de nuevas propiedades ópticas, eléctricas, químicas, ...

El importante esfuerzo de investigación y desarrollo tecnológico que actualmente se realiza sobre el vidrio en las tres direcciones principales:

- modificaciones en su propia composición,

- transformaciones de la superficie mediante tratamientos,

- asociación con otros materiales,
Le développement du verre appliqué à la construction commence pendant l'empire romain. Suite à la prolifération de fours et artisans verriers, apparaissent les premières applications sur pavés, plaques de recouvrement de murs ... en arrivant bientôt à la fermeture de trous.

L'homme a toujours eu une inquiétude: son habitat. En cherchant toujours la façon de se protéger des intempéries, des agressions de l'extérieur, de l'immixtion, ... mais sans se résigner à vivre dans l'isolement, dans l'obscurité, ... II a toujours essayé de conjuguer sa sécurité et sa protection avec l'utilité de la lumière, la chaleur, l'observation de l'extérieur, ... C'est ainsi qui nait la plus importante application du verre, dans la construction. Avec ses fonctions contradictoires: il sépare et rattache à la fois; il est inerte et ses effets sont variables; il donne légérété et harmonie; il est résistant; il compose avec la lumière des reflets, et il est transparent, ... il rend plus facile la grande expansion de l'architecture comme art et technique de la construction.

Les premières fenêtres connues proviennent des ruines de Pompeïa (Siècle I de l'ere chrétienne). Curieusement ces verres, d'une composition très semblable à l'actuelle et de surfaces déjà importantes (proches au $\mathrm{m}^{2}$ ), sont obtenus avec une technologie de coulée et pressage que l'on ne reprendra pas jusqu'au XVII siècle. En 1688 Saint-Gobain (France) commence à exploiter et exporter un nouveau procédé, de coulée du verre fondu et ensuite laminé, permettant d'obtenir des verres plats de grandes surfaces. C'est le début de l'industrialisation du verre.

\section{La symbiose verre-construction est déjà} consolidée, mais c'est, sans aucune doute, dans les dernières années, quand ce matériau s'est intégré de manière totale dans l'architecture créatrice, passant d'un état d'élément esthétique, ou un matériau transparent de séparation, à un matériau multifonctionnel. II combine parfaitement sa qualité principale, la transparence à la lumière, à des fonctions sélectives face à d'autres radiations, à l'isolation du bruit, de la chaleur, du feu, la résistance à l'impact ou l'effraction, à son comportement comme élément structurel, à l'apport de nouvelles propriétés optiques, électriques, chimiques etc...

L'important effort de recherche et développement technologique réalisé actuellement sur le verre est orienté dans trois directions principales:

- Modifications dans sa propre composition.

- Transformation de la surface au moyen de traitements.

- Association avec d'autres matériaux. 
TABLA I TABLE I

El vidrio (Le verre)

\begin{tabular}{|c|c|}
\hline $\begin{array}{l}\text { Con sus diferentes formas y procesos de fabricación } \\
\text { - PLANO: Acristalamientos, vehículos, decoración, etc. } \\
\text { - HUECO: Envases, vajillas, tubos, etc. } \\
\text { - FIBRAS: Aislamiento, tejidos, refuerzo de plásticos, etc. } \\
\text { - ESPECIALES: Óptica, telecomunicaciones, composites, etc. }\end{array}$ & $\begin{array}{l}\text { Sous ses différentes formes et procédés de fabrication } \\
\text { - PLAT: Vitrages, véhicules, décoration, etc. } \\
\text { - CREUX: Bouteilles, vaisselle, tubes, etc. } \\
\text { - FIBRES: Isolation, tissus, renforcement de plastiques, etc. } \\
\text { - SPECIAUX: Optique, télécommunications, composites, etc. }\end{array}$ \\
\hline $\begin{array}{l}\text { ES indispensable on la vida moderna } \\
\\
\text { - ARQUITECTURA. } \\
\text { - TRANSPORTES. } \\
\text { - USO DOMESTICO. } \\
\text { - ILUMINACIÓN. } \\
\text { - OPTICA. } \\
\text { - ELECTRÓNICA. } \\
\text { - ETC., ETC. }\end{array}$ & $\begin{array}{l}\text { Est indispensable dans la vie moderne } \\
\\
\text { - ARCHITECTURE. } \\
\text { - TRANSPORTS. } \\
\text { - USAGE DOMESTIQUE. } \\
\text { - ECLAIRAGE. } \\
\text { - OPTIQUE. } \\
\text { - ELECTRONIQUE. } \\
\text { - ETC., ETC. }\end{array}$ \\
\hline $\begin{array}{c}\text { Su utilización, cada día más extendida y diversificada, se } \\
\text { justifica por las posibilidades de combinar sus excelentes } \\
\text { propiedades }\end{array}$ & $\begin{array}{c}\text { Son utilisation, chaque jour plus étendue et diversifiée, qui } \\
\text { se justifie par les possibilités de combiner ses excellentes } \\
\text { propriétés }\end{array}$ \\
\hline $\begin{array}{l}\text { - OPTICAS: Transparencia, color, reflexión, etc. } \\
\text { - MECÁNICAS: Indeformabilidad, resist. a la abrasión, etc. } \\
\text { - TERMICAS: Aislamiento, refratariedad, resist. al fuego, etc. } \\
\text { - ACÚSTICAS: Atenuación acústica, aislamiento, etc. } \\
\text { - QUIMICAS: Estabilidad, resist. al ambiente, etc. } \\
\text { - ELÉCTRICAS: Resistividad, aislamiento, etc. }\end{array}$ & $\begin{array}{l}\text { - OPTIQUES: Transparence, cóleur, réflection, etc. } \\
\text { - MECANIQUES: Rigidité, résistance à l'abrasion, etc. } \\
\text { - THERMIQUES: Isolation, réfractarité, résistance au feu, etc. } \\
\text { - ACOUSTIQUES: Attenuation acoustique, isolation, etc. } \\
\text { - CHIMIQUES: Stabilité, résistance á l'ambiance, etc. } \\
\text { - ELECTRIQUES: Résistivité, isolement, etc. }\end{array}$ \\
\hline
\end{tabular}

permite dar respuesta a la demanda de nuevas aplicaciones y crecientes exigencias. Si además se tienen en cuenta algunos aspectos positivos de este material: Las materias primas para su fabricación son prácticamente inagotables; en general es recuperable; es inerte; no contamina; ... se entenderá mejor el continuo crecimiento de su utilización.

La importancia de este material está ratificada por sus numerosas aplicaciones, bajo diferentes formas y composiciones, gracias a la posibilidad de la combinación seleccionada de sus variadas propiedades. El Vidrio ha pasado así, de ser un producto interesante, a ser indispensable para satisfacer múltiples necesidades de la vida moderna (tabla I).

De las diversas familias de los vidrios considerados como convencionales interesan especialmente a la construcción aquéllos de mayor implantación, es decir:

\section{- El vidrio plano.}

- Los productos estructurales.

\section{— Las fibras de vidrio.}

Il permet d'apporter une réponse à la demande de nouvelles applications et à des exigences croissantes.

Compte tenu de certains aspects positifs de ce matériau: Les matières premières pour sa fabrication sont presque inépuisables; en général il est récupérable; il est inerte; ne contamine pas; ...alors on comprend mieux la croissance continue de son utilisation.

L'importance de ce matériau est ratifiée par ses nombreuses applications, sous des formes et compositions différentes, grâce à la possibilité de la sélection combinée de ses diverses propriétés. Ainsi, le verre est passé de l'état d'un produit intéréssant à celui d'indispensable pour satisfaire de multiples nécessites de la vie moderne. (Table I).

Des diverses familles de verres considérés comme conventionnels, ceux qui entéréssent plus spécialement à la construction sont ceux de plus grande diffusion, c'est à dire:

\section{- Le verre plat.}

\section{- Les produits structurels.}

\section{- Les fibres de verre.}


Aunque la industria de la construcción no es, en general, muy innovadora y acepta difícilmente los nuevos productos si no están ya exhaustivamente ensayados, son las crecientes exigencias y necesidades del usuario el principal factor desencadenante del importante desarrollo de los productos vidrieros en estos últimos años.

\section{EL VIDRIO PLANO EN LA CONSTRUCCION}

De forma genérica se entiende por "vidrio plano" una extensa variedad de productos que tienen en común su forma de placas o láminas de caras plano-paralelas.

Limitándose a los dos procesos de fabricación más representativos actualmente, puede hacerse una primera subdivisión:

"Vidrio plano flotado", obtenido por estirado del vidrio sobre un baño de estaño fundido, que se conforma en una banda continua de caras perfectamente planas, paralelas y pulidas y proporcionan una visión, a su través, sin distorsiones.

"Vidrio laminado o impreso", fabricado por laminación entre dos cilindros, conformado en banda continua con un dibujo o grabado en una de sus caras que produce translucidez y distorsión de los objetos vistos a través de él.

Siendo sus composiciones químicas muy parecidas, sus propiedades diferenciadoras son principalmente las ópticas.

Las transformaciones o tratamientos, en una segunda fase de la fabricación, dan lugar a la extensa variedad de productos finales:

Reflectantes (entre ellos los espejos); Antisolares; de Seguridad; de Aislamiento térmico; de Aislamiento acústico; de Color y Transmisión selectiva; Templados; Curvados; etc. etc.

El gran desarrollo tecnológico actual de esta industria y la fuerte competencia mundial existente fomentan la continua aparición de nuevos productos con funciones añadidas o mejoradas.

Desde su incorporación como material de construcción, al vidrio se le han reservado sus funciones originarias: la protección del exterior y la transmisión de la luz. La Arquitectura le añade la misión de mejorar la estética y el diseño. En la Construcción moderna se le hace participar además en la solución de nuevas exigencias: EI confort y la seguridad (tabla II).

El control de la luz es uno de los factores esenciales en la Arquitectura.
Etant donné que l'industrie de la construction n'est pas, en général, très innovatrice et accepte difficilement les nouveaux produits, s'ils n'on pas été essayés de façon exhaustive, ce sont les éxigences croissantes et les besoins des utilisateurs qui ont provoqué l'important développement des produits verriers de ces dernières années.

\section{LE VERRE PLAT DANS LA CONSTRUCTION}

D'une façon générique, on appelle "verre plat" à une grande variété de produits qui ont en commun leur forme de plaques à faces planes et parallèles.

Les deux processus de fabrication les plus representatifs actuellement, peuvent être décomposés comme suit:

"Verre flotté" obtenu par étirage du verre sur un bain d'etain fondu, formé en une bande continue à faces parfaitement planes, parallèles et polies qui permettent une vision sans distorsions.

"Verre coulé ou imprimé" fabriqué par laminage entre 2 cylindres, formé en bande continue avec un dessin sur une de ses faces qui fournit un produit translucide et provoque une distorsion des objets vus à travers lui.

Leurs compositions chimiques étant très semblables, les propriétés différentes entre les deux sont principalement optiques.

Dans une deuxième phase de la fabrication, les transformations ou traitements donnent lieu à une énorme variété de produits finaux. Réflechissants (parmi eux les miroirs); Antisolaires; de Sécurité; d'Isolation thermique; d'isolation acoustique; de Couleur et Transmission sélective; Trempés; Courbes; etc. etc.

Le grand développement technologique actuel de cette industrie et la forte concurrence mondiale existante favorisent la constante apparition de nouveaux produits avec des propriétés ajoutées ou améliorées.

Depuis son incorporation à la construction comme matériel de construction, le verre conserve toujours ses fonctions premières: la protection de l'extérieur et la transmission de la lumière. L'Architecture lui a ajouté la mission d'améliorer l'esthetique et le dessin. La construction moderne le fait participer aussi à la solution de nouvelles exigences. Le confort et la sécurité (Table II).

Un des facteurs principaux dans l'Architecture est le contrôle de la lumière. 
TABLA \| TABLE \|

Exigencias para el vidrio plano construcción (Exigences pour le verre plat construction)

\begin{tabular}{|l|l|l|l|}
\hline Estética y diseño & $\begin{array}{l}\text { Transparencia } \\
\text { Color/reflejos } \\
\text { Dimensiones/formas }\end{array}$ & Esthétique et dessin & $\begin{array}{l}\text { Transparence } \\
\text { Couleur/reflets } \\
\text { Dimensions/formes }\end{array}$ \\
\hline Confort & $\begin{array}{l}\text { Térmico } \\
\text { Acústico } \\
\text { Visual }\end{array}$ & Confort & $\begin{array}{l}\text { Thermique } \\
\text { Acoustique } \\
\text { Visuel }\end{array}$ \\
\hline Seguridad & $\begin{array}{l}\text { Constructiva } \\
\text { Bienes/personas } \\
\text { Duración }\end{array}$ & Sécurité & $\begin{array}{l}\text { Constructive } \\
\text { Biens/personnes } \\
\text { Durabilité }\end{array}$ \\
\hline
\end{tabular}

El vidrio, en esta primera misión contributiva a la estética y el diseño, permite manipular la luz a voluntad:

- Proporcionando la transparencia deseada con el color elegido.

- Facilitando los intercambios entre el interior y el exterior.

- Modificando la percepción del espacio: Reflejos; Transparencias; Penetración visual; Zonas de luz; etc.

- Dando forma y belleza al conjunto. Valorizando superficies y materiales.

- Fortaleciendo los signos de calidad y de standing.

La demanda de confort es cada vez mayor en la Construcción. El vidrio tiene aquí un papel importante:

- Posibilita el control de la transmisión luminosa y energética. Sirve a la vez de unión y separación (aislamiento) del medio exterior.

- En el aislamiento térmico (y la economía de energía):

- Permite el aprovechamiento de los aportes solares gratuitos.

- Limita las pérdidas térmicas hacia el exterior.

- Reduce el efecto de "pared fría".

- Permite conjugar sus demás funciones con el aislamiento acústico adecuado a las necesidades del local.

El vidrio responde también a las múltiples exigencias actuales en relación con la seguridad:
Dans cette 1. dre mission de contribution à l'esthetique et le dessin, le verre permet de manipuler la lumière à volonté:

- En procurant la transparence désirée avec la couleur choisie.

- En facilitant les échanges entre l'intérieur et l'extérieur.

- En modifiant la perception de l'espace: Réflets; Transparence; Pénetration visuelle; Zônes de lumière; etc.

- En donnat forme et beauté à l'ensemble. En valorisant les surfaces et les matériaux.

- En soulignant les signes de qualité et de standing.

La demande de Confort dans la Construction augmente chaque fois. Le verre a ici un rôle très important:

- Il rend possible le contrôle de la transmission lumineuse et energetique. II sert à la fois d'union et de séparation (isolation) d'avec le milieu extérieur.

\section{- Dans l'isolation thermique (et l'economie d'énergie):}

- Il permet de profiter des apports solaires gratuits.

- Il limite les pertes thermiques vers l'extèrieur.

- II réduit l'effet de "paroi froide".

- Il permet de conjuguer ses autres fonctions avec l'isolation acoustique nécéssitée par le local.

Le verre répond aussi aux multiples exigences actuelles en ce qui concerne la sécurité: 
- Seguridad, en primer lugar, como material de construcción con funciones estructurales resistentes:

- Participando activamente a soportar las solicitaciones termo-mecánicas del entorno (presión del viento, choques, dilataciones, radiación solar, etc.).

- Dando la solidez, ligereza, estanquidad... necesarias al edificio.

- Facilitando el ensamblado y la combinación con otros elementos de la construcción.

- La seguridad de personas y bienes, una preocupación en aumento en la Sociedad actual. El vidrio, lejos de su reputación generalizada de material "necesariamente frágil", se actualiza en productos para:

- Resistir los impactos, la rotura total, la penetración.

- Actuar como elemento antifracción/antirobo ( $y$ en casos necesarios como material transparente de blindaje contra proyectiles).

- Resistir el fuego y la propagación de las llamas.

- Absorber las radiaciones $X$ y $\gamma$ (con vidrios de composiciones no convencionales) para ventanas de reactores nucleares y de equipos de Rayos $X$.

- Su comportamiento al ambiente y en el tiempo es un acpecto más de la Seguridad. El vidrio se caracteriza por:

- Su garantía de inalterabilidad.

- La invariabilidad, en el tiempo, de sus características.

- La facilidad y bajo costo de su mantenimiento.

- En definitiva, su longevidad como material de construcción.

\subsection{Actualización de los productos de vidrio plano en la construcción}

Es evidente que un solo producto no puede satisfacer simultáneamente todas las funciones demandadas. Por ello, tanto los esfuerzos de desarrollo de la industria vidriera, como los de investigación en este campo, están orientados, en su mayor parte, a aumentar la funcionalidad del vidrio, a dotarle de nuevas propiedades y, en definitiva, a crear productos compuestos que
- Sécurité, tout d'abord, comme matériel de construction avec fonctions structurelles résistantes.

- En participant activement à supporter les sollicitations thermo-mécaniques de l'environnement (pression du vent, chocs, dilatations, radiation solaire, etc.).

- En donnant la solidité, la légèreté, l'etanchéité ... nécessaires à l'édifice.

- En facilitant l'assemblage et la combinaison avec d'autres élements de la construction.

- La sécurité des personnes et des biens est une préoccupation croissante dans la Société actuelle. Le verre, loin de sa réputation de matériel "nécessairement fragile" s'utilise actuellement dans des produits pour:

- Résister aux impacts, à la cassure totale, à la pénetration.

- Agir comme élement anti-effrraction/anti-vol (et en cas de nécessité comme matériel transparent de blindage contre les projectiles).

- Résister le feu et la propagation des flammes.

- Absorber les radiations $X$ et $\gamma$ (avec verres de compositions non conventionnelles) pour fenêtres de réacteurs nucléaires et pour équipements à Rayons $X$.

- Son comportement dans l'environnement et dans le temps est encore un autre aspect de Sécurité. Le verre se caracterérise par:

- Sa garantie d'inaltérabilité.

- L'invariabilité de ses caractéristiques au cours du temps.

- Un entretien facile et bon marché.

- En définitive, sa longévité comme matériel de construction.

\subsection{Actualisation des produits de verre plat dans la construction}

Evidémment un seul produit ne peut pas satisfaire d'une façon simultanée toutes les fonctions demandées. En conséquence, tant les efforts de développement industriel de l'industrie verrière, que les efforts de recherche dans ce domaine, sont orientés pour la plupart vers la fonctionnalité du verre, en le dotant de nouvelles propriétés et en définitive, créer des produits composés qui 
respondan mejor y de forma más completa a las necesidades del utilizador.

Los nuevos productos surgen, a partir del vidrio más convencional, por el efecto de:

\section{- Las modificaciones en su composición.}

- Las transformaciones en su superficie.

\section{- La asociación con otros productos,}

y, más frecuentemente, por la asociación de varias de estas acciones o la combinación de varios productos. peuvent répondre mieux et d'une façon plus complète aux besoins de l'utilisateur.

Les nouveaux produits font leur apparition à partir des verres plus conventionnels, par:

- Les modifications dans la composition.

\section{- Les transformations de la surface.}

\section{- L'association avec d'autres produits,}

et plus fréquemment par l'association des différentes actions ou par la combinaison de divers produits.

TABLA III

Acciones I + D en vidrio plano

\begin{tabular}{|c|c|c|c|}
\hline Actuaciones & \multicolumn{2}{|c|}{ Modificación de propiedades } & Productos derivados \\
\hline \multirow{5}{*}{$\begin{array}{l}\text { En masa } \\
\text { (Comp. vitrificable } \\
\text { y tratamientos) }\end{array}$} & Ópticas & $\begin{array}{l}\text { Transmisión } \\
\text { Color }\end{array}$ & $\begin{array}{l}\text { V. extra-blancos (incoloros) } \\
\text { V. absorbentes (de color) }\end{array}$ \\
\hline & Térmicas & $\begin{array}{l}\text { Choque térmico } \\
\text { Resistencia al fuego }\end{array}$ & V. corta-fuegos \\
\hline & Químicas & Resistencia ataque químico & V. normales \\
\hline & Acústicas & Modificación espesor & V. normales \\
\hline & Mecánicas & $\begin{array}{l}\text { Resistencia a la flexión } \\
\text { Choque y rotura }\end{array}$ & V. templados \\
\hline \multirow{4}{*}{$\begin{array}{l}\text { En superficie } \\
\text { (Tratamientos y capas) }\end{array}$} & Ópticas & $\begin{array}{l}\text { Reflexión luminosa } \\
\text { Reflexión N.I.R. } \\
\text { Foto/electro-cromismo }\end{array}$ & $\begin{array}{l}\text { V. reflectantes } \\
\text { V. de reflexión selectiva } \\
\text { V. antisolares } \\
\text { V. de color y transm. } \\
\text { variables }\end{array}$ \\
\hline & Térmicas & Emisividad (F.I.R.) & V. no emisivos \\
\hline & Químicas & $\begin{array}{l}\text { Desalcalinización } \\
\text { Regulación } \mathrm{pH}\end{array}$ & $\begin{array}{l}\text { V. resistentes al } \\
\text { envejecimiento }\end{array}$ \\
\hline & Eléctricas & $\begin{array}{l}\text { Conductividad } \\
\text { Fotovoltaismo }\end{array}$ & $\begin{array}{l}\text { V. auto-calefactores } \\
\text { V. antena } \\
\text { V. fotovoltaico }\end{array}$ \\
\hline \multirow{3}{*}{$\begin{array}{l}\text { Con materiales } \\
\text { compuestos } \\
\text { (Comp. vidrio plástico) }\end{array}$} & Ópticas & Transmisión & V. de color \\
\hline & Mecánicas & $\begin{array}{l}\text { Resistencia al choque y a } \\
\text { la efracción }\end{array}$ & $\begin{array}{l}\text { V. de seguridad (anti robo, } \\
\text { anti-bala) } \\
\text { V. antilacerantes }\end{array}$ \\
\hline & Químicas & Repulsión del agua & V. anti-vaho \\
\hline \multirow{2}{*}{$\begin{array}{l}\text { Unión de vidrios } \\
\text { (Acristalamientos múltiples) }\end{array}$} & Térmicas & $\begin{array}{l}\text { Variación de } \mathrm{K} \\
\text { Aislamiento térmico }\end{array}$ & $\begin{array}{l}\text { V. acristalamientos } \\
\text { múltiples } \\
\text { V. ID. con gases o vacío }\end{array}$ \\
\hline & Acústicas & Atenuación acústica & V. aislantes acústicos \\
\hline
\end{tabular}


TABLE III

Actions $R$ et $D$ en verre plat

\begin{tabular}{|c|c|c|c|}
\hline Modifications & \multicolumn{2}{|c|}{ Changement de proprietes } & Produits obtenus \\
\hline \multirow{5}{*}{$\begin{array}{l}\text { En masse } \\
\text { (Composition vitrificable } \\
\text { et traitements) }\end{array}$} & Optiques & $\begin{array}{l}\text { Transmission } \\
\text { Couleur }\end{array}$ & $\begin{array}{l}\text { V. extrablancs (incolores) } \\
\text { et absorbants (de couleur) }\end{array}$ \\
\hline & Thermiques & $\begin{array}{l}\text { Chocs thermiques } \\
\text { Résistance au feu }\end{array}$ & V. coupe-feu \\
\hline & Chimiques & Resist. à l'attaque chim. & V. ordinaires \\
\hline & Acoustiques & Modificat. d'épaisseur & V. ordinaires \\
\hline & Mécaniques & $\begin{array}{l}\text { Résistance à la flexion, } \\
\text { aux chocs et à la fracture }\end{array}$ & V. trempés \\
\hline \multirow{4}{*}{$\begin{array}{l}\text { De la surface } \\
\text { (traitements et couches) }\end{array}$} & Optiques & $\begin{array}{l}\text { Réflection lumineuse } \\
\text { Réflection N.I.R. } \\
\text { Photo électro chromisme }\end{array}$ & $\begin{array}{l}\text { V. reflechissants } \\
\text { V. à reflect sélective } \\
\text { V. antisolaires } \\
\text { V. de couleur et transm. } \\
\text { variables }\end{array}$ \\
\hline & Thermiques & Emissivité & V. non emissis \\
\hline & Chimiques & $\begin{array}{l}\text { Desalcalinisation } \\
\text { régulation } \mathrm{pH}\end{array}$ & $\begin{array}{l}\text { V. resit. au } \\
\text { viellissement }\end{array}$ \\
\hline & Electriques & $\begin{array}{l}\text { Conductivité } \\
\text { Photovoltaisme }\end{array}$ & $\begin{array}{l}\text { V. auto chauffants } \\
\text { V. antennes } \\
\text { V. photo voltaiques }\end{array}$ \\
\hline \multirow{3}{*}{$\begin{array}{l}\text { Avec des matériaux } \\
\text { composites } \\
\text { (Combinaison } \\
\text { verre-plastique) }\end{array}$} & Optiques & Transmission & V. de couleur \\
\hline & Mécaniques & $\begin{array}{l}\text { Résistance aux chocs } \\
\text { et à l'éfraction }\end{array}$ & $\begin{array}{l}\text { V. de sécurite (anti vol et } \\
\text { anti balles) } \\
\text { V. anti coupure }\end{array}$ \\
\hline & Chimiques & Répulsion de l'eau & V. anti-buée \\
\hline \multirow{2}{*}{$\begin{array}{l}\text { Union de verres } \\
\text { (Vitrages multiples) }\end{array}$} & Thermiques & $\begin{array}{l}\text { Variation du } k \\
\text { isolation thermique }\end{array}$ & $\begin{array}{l}\text { Vitrages multiples } \\
\text { Vitrage avec gaz du vide }\end{array}$ \\
\hline & Acoustiques & Atténuation acoustique & $\mathrm{V}$. isolants acoustiques \\
\hline
\end{tabular}

En la tabla III se recoge, de forma muy esquemática, una relación de productos derivados de la modificación de ciertas propiedades del vidrio a partir de actuaciones diversas en su masa, en su superficie o mediante combinación entre sí o con otros productos.

\subsubsection{Nuevos vidrios por modificación de la formulación}

Los vidrios convencionales de silicato tienen una formulación generalmente optimizada en función del proceso de fabricación y de sus usos más comunes.
Dans la Table III figure une liste de produits dérivés de la modification de certaines propriétés du verre à partir de changements effectués dans la masse, dans la surface ou au moyen de la combinaison avec d'autres verres ou avec d'autres produits.

\subsubsection{Nouveaux verres par modification de la formulation}

Les verres conventionnels de silicate ont généralement une formulation optimisée en fonction du procédé de fabrication et de ses usages les plus communs. 
TABLA IV TABLE IV

Propiedades comunes a los productos de vidrio plano (Proprietes communes aux produits de verre plat)

\begin{tabular}{|c|c|c|c|}
\hline \multicolumn{2}{|c|}{$\begin{array}{l}\text { A) Propiedades ópticas } \\
\text { (vidrio } 10 \mathrm{~mm} \text { de espesor incoloro) }\end{array}$} & \multicolumn{2}{|c|}{$\begin{array}{l}\text { A) propriétés optiques } \\
\text { (verre incolore de } 10 \mathrm{~mm} \text { d'épaisseur) }\end{array}$} \\
\hline $\begin{array}{l}\text { Indice de refracción } \\
\text { Transmisión luminosa } \\
\left.\text { Transmisión energética ( }{ }^{\star}\right) \\
\text { Factor solar (FS) } \\
\text { (") Transmisión U.V.: nula hasta } \\
310 \mathrm{~mm} \text {; Transmision I.R.: } \\
\text { prácticamente nula a partir de } \\
2.000 \mathrm{~nm}\end{array}$ & $\begin{array}{l}n=1,52 \\
88 \% \\
76 \% \\
82\end{array}$ & $\begin{array}{l}\text { Indice de réfraction } \\
\text { Transmission Lunineuse } \\
\text { Transm. energétique }\left(^{*}\right) \\
\text { Facteur solaire (FS) } \\
\left(^{*}\right) \text { Transm. UV nulle jusque } \\
310 \mathrm{~nm} \text {; Transm. IR practiquem. } \\
\text { nulle à partir de } 2.000 \mathrm{~nm}\end{array}$ & $\begin{array}{l}n=1,52 \\
88 \% \\
76 \% \\
82\end{array}$ \\
\hline \multicolumn{2}{|c|}{ B) Propiedades mecánicas } & \multicolumn{2}{|c|}{ B) Propriétés mécaniques } \\
\hline $\begin{array}{l}\text { Densidad } \\
\text { Dureza (escala de Mohs) } \\
\text { Resistencia a la abrasión } \\
\text { Elastic. (mod. de Young) } \\
\text { Resist. a la tracción } \\
\text { Resist. a la compresión } \\
\text { Resist. a la flexión }\end{array}$ & $\begin{array}{l}d=2,5 \mathrm{~kg} / \mathrm{dm}^{3} \\
\approx 6,5 \\
16 \mathrm{v} .>\mathrm{q} \cdot \text { granito } \\
E=7,3 \cdot 10^{5} \mathrm{~kg} / \mathrm{cm}^{2} \\
400+1.500 \mathrm{~kg} / \mathrm{cm}^{2} \\
>10.000 \mathrm{~kg} / \mathrm{cm}^{2} \\
100 \div 500 \mathrm{~kg} / \mathrm{cm}^{2}\end{array}$ & $\begin{array}{l}\text { Densité } \\
\text { Dureté (échelle de Mohs) } \\
\text { Résistance a L'abrasion } \\
\text { Elaticité (module d'Young) } \\
\text { Résistance à la traction } \\
\text { Résistance à la compresion } \\
\text { Résistance à la flexion }\end{array}$ & $\begin{array}{l}d=2,5 \mathrm{~kg} / \mathrm{dm}^{3} \\
\approx 6,5 \\
16 \mathrm{v} .>\mathrm{q} \cdot \text { granito } \\
E=7,3 \cdot 10^{5} \mathrm{~kg} / \mathrm{cm}^{2} \\
400+1.500 \mathrm{~kg} / \mathrm{cm}^{2} \\
>10.000 \mathrm{~kg} / \mathrm{cm}^{2} \\
100 \div 500 \mathrm{~kg} / \mathrm{cm}^{2}\end{array}$ \\
\hline \multicolumn{2}{|c|}{ C) Propiedades térmicas } & \multicolumn{2}{|c|}{ C) Propriétés thermiques } \\
\hline $\begin{array}{l}\text { Calor específico } \\
\text { Coef. de dilatación lineal } \\
\text { Conductividad térmica } \\
\text { Resist. al choque térmico } \\
\text { en productos templados }\end{array}$ & $\begin{aligned} \mathrm{C} & =0,19 \mathrm{cal} . / \mathrm{g} \\
\alpha & =8 \times 10^{-6} \\
\lambda & =0,86 \mathrm{kcal} / \mathrm{h} \cdot \mathrm{m}^{2} \cdot{ }^{\circ} \mathrm{C} \\
& \approx 60^{\circ} \mathrm{C} \\
& \approx 240^{\circ} \mathrm{C}\end{aligned}$ & $\begin{array}{l}\text { Chaleur spécifique } \\
\text { Coef. de dilatation linéaire }\end{array}$ & $\begin{array}{l}\mathrm{C}=0,19 \mathrm{cal} . / \mathrm{g} \\
\alpha=8 \times 10^{-6} \\
\lambda=0,86 \mathrm{kcal} / \mathrm{h} \cdot \mathrm{m}^{2} \cdot{ }^{\circ} \mathrm{C} \\
\approx 60^{\circ} \mathrm{C} \\
\approx 240^{\circ} \mathrm{C}\end{array}$ \\
\hline \multicolumn{2}{|c|}{ D) Propiedades acústicas } & \multicolumn{2}{|c|}{ D) Propriétés acoustiques } \\
\hline $\begin{array}{l}\text { Indices de atenuación } \\
\text { acústica (vidrio simple de } \\
10 \mathrm{~mm} \text { de espesor) } \\
\text { A ruido de carretera } \\
\text { A ruido rosa } \\
\text { Velocidad del sonido }\end{array}$ & $\begin{array}{l}35 \mathrm{~dB}(\mathrm{~A}) \\
38 \mathrm{~dB}(\mathrm{~A}) \\
5 \div 6 \mathrm{~km} / \mathrm{s}\end{array}$ & $\begin{array}{l}\text { Indices d'attenuation } \\
\text { acoustique (verre simple } \\
\text { d'épaisseur) } \\
\text { Bruit routier } \\
\text { Bruit rose } \\
\text { Vitesse du son }\end{array}$ & $\begin{array}{l}35 \mathrm{~dB}(\mathrm{~A}) \\
38 \mathrm{~dB}(\mathrm{~A}) \\
5 \div 6 \mathrm{~km} / \mathrm{s}\end{array}$ \\
\hline \multicolumn{2}{|c|}{ E) Propiedades eléctricas } & \multicolumn{2}{|c|}{ E) propriétés électriques } \\
\hline $\begin{array}{l}\left.\text { Conductividad (a } 243^{\circ} \mathrm{C}\right) \\
\text { Resistividad }\left(\text { a } 25^{\circ} \mathrm{C}\right) \\
\text { Constante dieléctrica } \\
\text { Rigidez dieléctrica }\end{array}$ & $\begin{array}{l}\mathrm{K} \approx 1 \cdot 10^{-8} \Omega^{-1} \cdot \mathrm{m}^{-1} \\
\rho \approx 5 \cdot 10^{13} \Omega \cdot \mathrm{m} \\
\varepsilon=7,1 \\
40 \mathrm{kV} / \mathrm{cm}\end{array}$ & $\begin{array}{l}\text { Conductivité (à } 243^{\circ} \mathrm{C} \text { ) } \\
\left.\text { Resistivité (à } 25^{\circ} \mathrm{C}\right) \\
\text { Constante diélectrique } \\
\text { Rigidité diélectrique }\end{array}$ & $\begin{array}{l}K \approx 1 \cdot 10^{-8} \Omega^{-1} \cdot \mathrm{m}^{-1} \\
\rho \approx 5 \cdot 10^{13} \Omega \cdot \mathrm{m} \\
\varepsilon=7,1 \\
40 \mathrm{kV} / \mathrm{cm}\end{array}$ \\
\hline
\end{tabular}

Son sus propiedades y características, que se recuerdan en la tabla IV, los que han permitido a este material mantener una progresión continua a medida que los medios de producción lo han permitido.

Basta recordar, por comparación con otros materiales de construcción, como comentario simplificado de la tabla IV, que:

- Su propiedad fundamental es la transparencia a la luz (88\% de transmision luminosa para un vidrio incoloro de $10 \mathrm{~mm}$ de espesor) con una Opacidad casi total a la radiación UV (de longitud de onda inferior a $310 \mathrm{~nm}$ ) y una
Ce sont les propriétés et caractéristiques de ce matériau qui se trouvent dans la Table IV qui ont permis à ce matériau de maintenir une progression continue au fur et à mesure que les moyens de production l'ont permis.

Il suffit de rappeler, par comparaison avec d'autres matériaux de construction, afin de commenter simplement la Table IV, que:

- Sa propriéte fondamentale est la transparence à la lumière (88\% de transmission lumineuse pour le Verre clair de $10 \mathrm{~mm}$. d'épaisseur) avec une opacité presque totale au rayonnement UV (de longueur d'onde 
reducción en el IR (a partir de 2,5 $\mu \mathrm{m}$ y prácticamente nula para $\lambda \geq 5 \mu \mathrm{m}$ ).

- Su Densidad $(2,5)$ es próxima a la del aluminio y un tercio de la del acero.

- La Resistencia a la abrasión es aproximádamente 16 veces superior a la del granito.

- Elasticidad igual a las del aluminio y latón, un tercio de la del acero y triple de la del hormigón.

- Resistencia a la tracción: 10 veces inferior al acero y 20 veces superior al hormigón.

- Resistencia a la compresión similar a la del acero.

- Mala conducción del calor: 400 veces menor que la del cobre.

- Buen aislante acústico y excelente aislante eléctrico.

Modificaciones importantes de algunas de estas características solamente se consiguen mediante cambios sustanciales en la matriz vítrea, dando lugar a nuevas familias de vidrios considerados aún como especiales por su escasa aplicación industrial.

Entre los vidrios no convencionales que progresivamente pueden ir integrándose en la construcción, aunque con una difusión restringida por la dificultad de su fabricación o por su elevado precio, se encuentran los siguientes:

\section{- Vidrios de bajo coeficiente de dilatación}

Los más conocidos, los llamados Borosilicatos, por ser el $\mathrm{B}_{2} \mathrm{O}_{2}$ y el $\mathrm{SiO}_{2}$ los óxidos que comparten el papel de formadores de la red vítrea, contienen muy bajas cantidades de fundentes $\left(\mathrm{Na}_{2} \mathrm{O}\right)$ y relativamente elevadas de estabilizantes $\left(\mathrm{Al}_{2} \mathrm{O}_{3}\right)$. Se consiguen así vidrios fusibles (aunque a temperaturas algo más elevadas que los convencionales), muy estables químicamente y con bajos coeficientes de dilatación, lo que equivale a buena resistencia a los choques térmicos.

Esta última propiedad es la que ha extendido la utilización de estos vidrios en usos de laboratorio y domésticos. En la Construcción se proponen como solución de tabiques o mamparas transparentes para uso como corta-fuegos.

\section{- Los vidrios cerámicos o vitro-cerámicos}

En los que se asocian las propiedades del vidrio y las de las cerámicas mediante la generación de inférieure à $310 \mathrm{~nm}$ ) et une réduction dans I'IR (à partir de 2,5 $\mathrm{m}$ et presque nulle pour $\lambda \geq 5 \mu \mathrm{m}$ ).

- Sa densité $(2,5)$ est proche à celle de l'Aluminium et vaut un tiers de celle de l'Acier.

- La résistance à l'abrasion est environ 16 fois supérieure à celle du Granit.

- Même élasticité que l'Aluminium et le Laiton, un tiers de celle de l'Acier, et le triple que celle du Béton.

- Résistance aux contraintes d'extension: 10 fois moins que l'Acier et 20 fois plus que le Béton.

- Résistance à la compressión similare à celle de l'Acier.

- Mauvaise conduction de la chaleur: 400 fois moins que le Cuivre.

- Bon isolant acoustique/Excellent isolant électrique.

Certaines caractériques peuvent être modifiées de manière importante en réalisant des variations substantielles dans la matrice verrière, et on obtient ainsi de nouvelles familles de verres considérés spéciaux à cause de leur faible diffusion industrielle.

Parmi les verres non conventionnels pouvant être intégrés dans la construction, mais ayant une diffusion restreinte à cause des difficultés de fabrication ou de leur coût élevé, on peut citer les suivants:

\section{- Verres a bas coefficient de dilatation}

Les plus connus sont, les Borosilicates, étant donné que la $\mathrm{B}_{2} \mathrm{O}_{2}$ et le $\mathrm{SiO}_{2}$ sont les oxydes qui forment le réseau vitreux, et contiennent de trés faibles quantités de fondants $\left(\mathrm{Na}_{2} \mathrm{O}\right)$ et de quantités rélativement élevées de stabilisants $\left(\mathrm{Al}_{2} \mathrm{O}_{3}\right.$ ). On obtient ainsi des verres fusibles (mais à des températures un peu plus élevées que celles des verres conventionnels), très stables chimiquement et avec des coefficients de dilation bas, c'est à dire avec une bonne résistance aux chocs thermiques.

Compte tenu de cette dernière propriété, ces verres sont les plus utilisés par les laboratoires et les ménages. Dans la construction ils sont utilisés pour faire des cloisons ou paravents transparents servant comme coupe-feu.

\section{- Les verres céramiques au vitro-céramiques}

Dans ces verres il y a une association des propriétés du verre et de celles des céramiques 
núcleos o fases cristalinas dentro de la fase vítrea.

En general, después de la fusión de la composición conteniendo pequeñas cantidades de agentes nucleantes $\left(\mathrm{TiO}_{2}, \mathrm{P}_{2} \mathrm{O}_{5}, \mathrm{ZrO}_{2}, \ldots\right)$ y de la conformación del vidrio, se somete a éste a un ciclo térmico que facilite la formación de núcleos y el crecimiento de cristales hasta el tamaño deseado (microcristales).

Son bastante conocidos algunos de estos productos vitrocerámicos en usos domésticos o de laboratorio y en aplicaciones muy especiales (p. ej. grandes lentes de telescopios con vitrocerámicos transparentes de coeficiente de dilatación nulo).

Su aplicación a la construcción se hará también en usos muy particulares donde sea necesario aprovechar su excelente resistencia térmica y mecánica.

\section{- Vidrios para absorción de radiaciones}

Están ligados casi exclusivamente a la construcción en la industria nuclear. Se utilizan para las ventanas de las células con fuentes radioactivas donde es necesaria la vigilancia y la manipulación a distancia.

Dado que el poder de absorción de la radiación $\gamma$ es función de la masa del material interpuesto, estos vidrios especiales, obtenidos con contenidos elevados de $\mathrm{PbO}$, tienen densidades del orden de 5 (doble de la de los vidrios comunes) y se utilizan en espesores elevados. Un acristalaminto para este uso, compuesto por varias placas de vidrio, puede llegar a tener un espesor total superior a un metro.

En los vidrios convencionales las modificaciones de su composición se hacen, en general, para ajustar los parámetros influyentes en la conformación a las exigencias del proceso de fabricación. Pero también se hacen variaciones de componentes, principalmente los llamados "colorantes", para alterar voluntariamente las características espectrofotométricas del vidrio y ajustarlas a la funcionalidad que se desea obtener.

Son principalmente los iones de los metales de transición contenidos en los vidrios los responsables de ciertas bandas de absorción a determinadas longitudes de onda. Aprovechando este efecto, mediante la adición de ciertos óxidos metálicos $\left(\mathrm{Fe}_{2} \mathrm{O}_{3}, \mathrm{CoO}, \mathrm{Cr}_{2} \mathrm{O}_{3}, \mathrm{~N}_{\mathrm{i}} \mathrm{O}\right.$, etc.), pueden modificarse a voluntad tanto su color como su transmitancia lo que permite actuar sobre la funcionalidad tanto en el aspecto "estético" como en el de "confort térmico y visual". Las au moyen de la génération de noyaux ou phases cristallines dans la phase verrière.

Généralement, après la fusion de la composition qui contient de petites quantités d'agents nucléants $\left(\mathrm{TiO}_{2}, \mathrm{P}_{2} \mathrm{O}_{5}, \mathrm{ZrO}_{2}, \ldots\right)$ et la conformation du verre, il est soumis à un cycle thermique afin de faciliter la formation de noyaux et la croissance de cristraux jusqu'à la taille souhaitée (microcristaux).

Ces produits vitrocéramiques sont assez connus pour les usages ménagers ou de laboratoire et pour des applications spéciales (p. ex., lentilles de télescope avec des vitrocéramiques transparents à coefficient de dilatation nulle).

Ils seront appliqués dans la construction pour des usages trés particuliers ou il faudra profiter de leur excellente résistance thermique et mécanique.

\section{- Verres pour absorption de radiations}

Ils sont liès presque exclusivement à la construction dans l'industrie nucléaire. Ils s'utilisent pour les fenêtres des cellules à sources radiactives où la surveillance et la manipulation doivent se faire à distance.

Etant donné que le pouvoir d'absorption de la radiation $\Gamma$ est fonction de la masse du matériel interposé, ces verres spéciaux, obtenus avec des pourcentages élevés de PbO ont des densités de l'ordre de 5 (le double que celle des verres communs) et ils sont utilisés avec de fortes épaisseurs. Un vitrage pour cette utilisation, composé de diverses plaques de verre, peut atteindre une épaisseur totale supérieure à un mètre.

Dans les verres conventionnels les

modifications de leur composition se font, en général, en ajustant les paramètres influents avec le processus de fabrication. Mais on réalise aussi des variations de composants, principalement de "colorants", pour altérer volontairement les caractéristiques spectrophotométriques du verre et les ajuster à la valeur souhaitée.

Ce sont principalement les ions des métaux de transition contenus dans les verres qui sont responsables des bandes d'absorbtion à des longueurs d'ondes detérminées. A l'aide de cet effet, et moyennant l'addition de certains oxydes métalliques $\left(\mathrm{Fe}_{2} \mathrm{O}_{3}, \mathrm{CoO}, \mathrm{Cr}_{2} \mathrm{O}_{3}, \mathrm{NiO}\right.$, etc.) on peut modifier à volonté la couleur et la transmittance, ce qui permet d'agir sur la fonctionnalité aussi bien sur l'aspect "Esthétique" que celui du "confort thermique et visuel". Les 
posibilidades teóricas de vidrios diferentes (desde el incoloro al opaco por máxima absorción) son ilimitadas. Solamente, la pureza de las materias primas y el propio proceso de fabricación limitan estas posibilidades.

Como ejemplo de vidrios de este tipo, con aplicaciones diversas en la construcción, pueden citarse los vidrios incoloros, los vidrios de color y absorbentes (tipo "PARSOL") y los vidrios funcionales muy absorbentes. En la Fig. 1 se representan las curvas de transmitancia espectral de tres de estos vidrios.

Para valorar la utilidad de este tipo de vidrios es preciso recordar los dos componentes asociados:

- El Sol, como fuente de radiaciones que proporcionan luz y calor. Al nivel de la tierra, estas radiaciones se extienden entre longitudes de onda de 0,3 a 2,2 $\mu \mathrm{m}$. (En la Fig. 1 se representa, como referencia, la curva de distribución espectral establecida por Parry Moon).

La distribución aproximada de la energía es: 5 $\%$ en la región UV $(\lambda<0,38 \mu \mathrm{m}) ; 50 \%$ en la región visible (de 0,38 a $0,78 \mu \mathrm{m}$ ) y $45 \%$ en el IR (a partir de $0,78 \mu \mathrm{m}$ ). possibilités thermiques de différents verres (depuis le verre clair au verre opaque par maximum absorption) sont illimitées. Seule la pureté des matières premières et le processus de fabrication lui même limitent ces possibilités.

Comme exemple de verres de ce type, avec différentes applications dans la construction, on peut mentionner les verres INCOLORES, les verres colorés et absorbants (type "PARSOL") et les verres fonctionnels très absorbants. Sur la Fig. 1 sont répresentées les courbes de transmitance spectrale de trois de ces verres.

Pour évaluer l'utilité de ce type de verres il faut rappeler les deux effects associés:

- Le Soleil comme source de radiations en propertimment lumière et chaleur. Au niveau de la terre, ces radiations s'étendent entre les longueurs d'onde de 0,3 à 2,2 $\mu \mathrm{m}$ (Sur la Fig. 1 on a répresenté, comme réference, la courbe de distribution spectrale établie par Parry Moon).

La distribution approximative de l'énergie est 5 $\%$ dans la région UV $(\lambda<0,38 \mu \mathrm{m}), 50 \%$ dans la région visible (de 0,38 à $0,78 \mu \mathrm{m}$ ) et $45 \%$ dans I'IR (à partir de $0,78 \mu \mathrm{m}$ ).

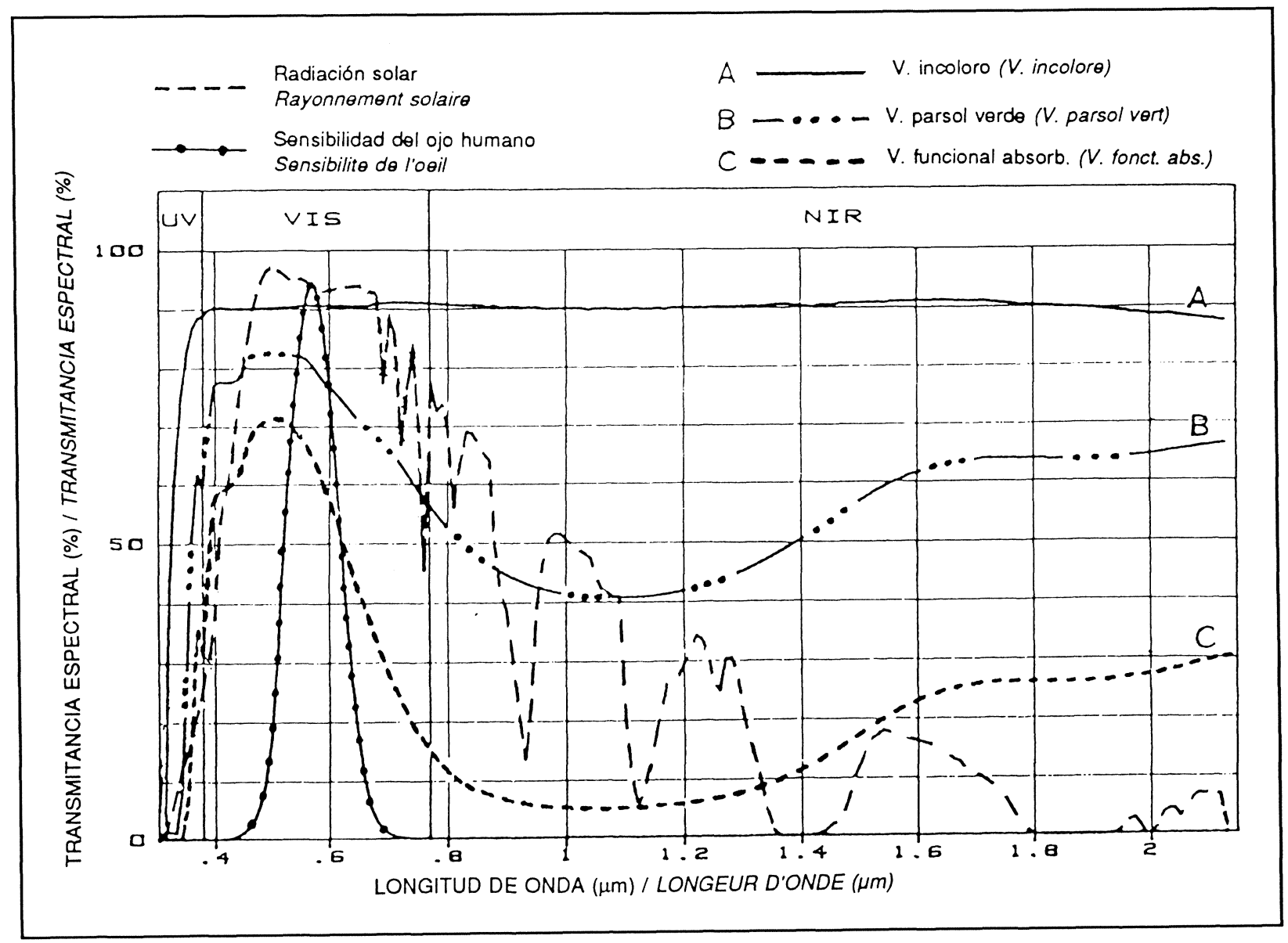

Fig. 1 
- La respuesta del ojo humano a una radiación de $\lambda$ dada. Se representa también en la Fig. 1 mediante la curva de sensibilidad relativa. La eficacia del ojo es máxima para $\lambda=0,55$ $\mu \mathrm{m}$ (zona de verdes-amarillos).

La sensación luminosa (respuesta del ojo) recibida a través del acristalamiento corresponde a la energía recibida ponderada por el factor de transmisión del vidrio y el factor de eficacia del ojo.

La cantidad de energía que atraviesa el acristalamiento y se transforma en calor está definida por el factor solar (Fig. 2) que corresponde a la suma de la energía solar transmitida directamente a través del vidrio $(T)$ y la parte de la absorbida (A) por él e irradiada hacia el interior (Ai) en relación con el total de energía incidente.

Las características particulares y empleo de los tres vidrios tipo, cuyas curvas de transmisión se representan en la Fig. 1 son:

\section{A) Vidrios incoloros tipo "PLANILUX"}

Son muy frecuentemente utilizados en la
- La réponse de l'oeil humain à une radiation $\lambda$ donnée. Elle est aussi répresentée sur la Fig. 1 au moyen de la courbe de sensibilité rélative L'efficacité de l'oeil est maximum pour $\lambda=0,55 \mu \mathrm{m}$ (zône des verts-jaunes).

La sensation lumineuse (réponse de l'oeil) reçue à travers le vitrage correspond à l'énergie reçue pondérée par le facteur transmission du verre et le facteur de l'efficacité de l'oeil.

La quantité d'énergie que traverse le vitrage est transformée en chaleur, elle est définie par le facteur solaire (Fig. 2) égale à l'addition de l'énergie solaire transmise directement au travers du verre $(T)$ et la partie absorbée $(A)$ par celui-ci et rayonnée vers l'intérieur (Ai) par rapport au total de l'énergie incidente.

Les caractéristiques particulières et l'emploi des 3 verres type, dont les courbes de transmission sont répresentées dans la Fig. 1 sont les suivantes:

\section{A) A verres clairs type "PLANILUX"}

Utilisés surtout dans la construction. II s'agit de

Esquema del comportamiento de la energía Solar que incide sobre un vidrio (Schéma du comportement de L'énergie Solaire incidente sur un verre)

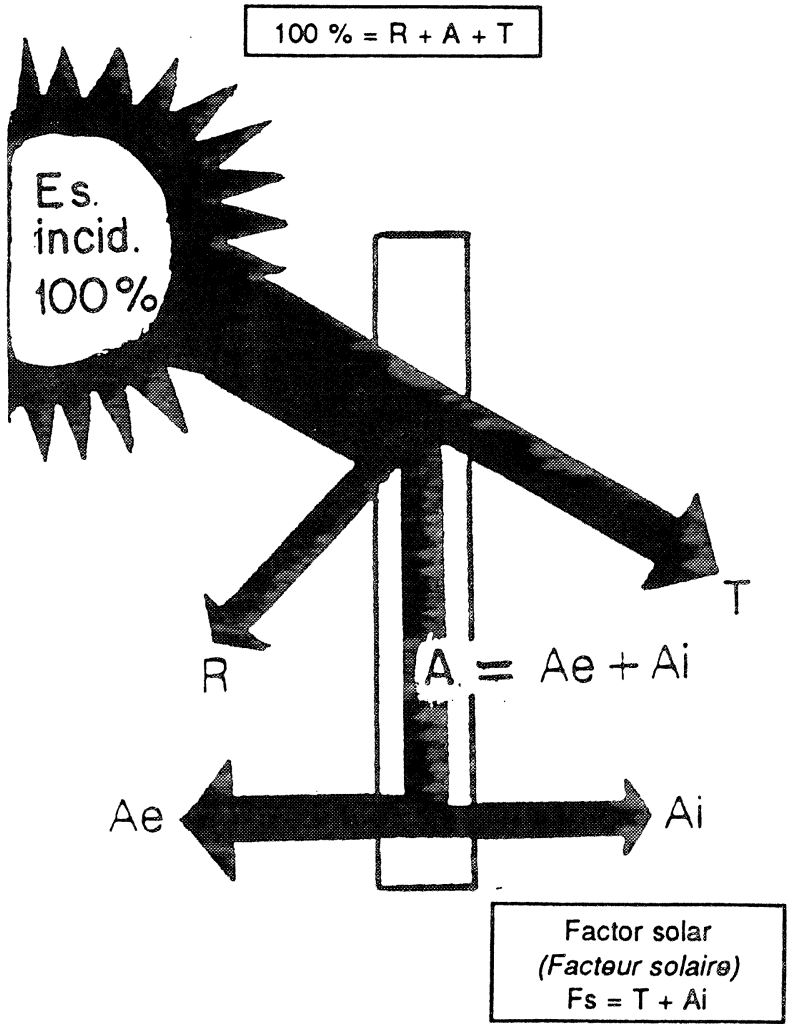

$\mathrm{R}=$ Factor de reflexión (Facteur de Réflexion)

$T$ = Factor de transmisión (Facteur de Transmision)

$\mathrm{Ae}=$ Absorción reenviada al exterior (Absortion réemise vers l'extérieur)

$\mathrm{Ai}$ = Absorción reenviada al interior (Absortion réemise vers l'intérieur) 
construcción. Son vidrios de elevada transmisión luminosa y energética. (Para e $<10 \mathrm{~mm}$, TL 90 $\%$ y $F S>0,8$ ).

Son vidrios adecuados para facilitar los aportes luminosos y energéticos solares.

Como vidrio especial, dentro de este grupo, está el extra-blanco, cuya característica principal es su extremada transparencia y pureza. Su utilización más conocida en la Pirámide del Museo de Louvre ha permitido el empleo de placas de $20 \mathrm{~mm}$ de espesor $(10+10)$ no alterando los matices cromáticos del entorno y dando una apariencia de ligereza a la construcción. Estos vidrios, con una absorción energética solamente del órden del $1 \%$, se utilizan también en equipos de recuperación y captación de la energía solar.

\section{B) Vidrios absorbentes "PARSOL"}

Son vidrios muy utilizados en la construcción dentro de la gama de protección solar. Son vidrios de color.

En éstos, una parte importante de la radicación solar incidente ( $50 \%$ para $6 \mathrm{~mm}$ de espesor), es absorbida por el vidrio y posteriormente remitida en forma de IR, tanto hacia el exterior como al interior, en proporciones que dependen de las velocidades del aire y de las temperaturas.

Los valores de $T_{L}$ y $F S$ (muy variables con el espesor) se indican en la tabla $V$.

\section{C) Vidrios funcionales muy absorbentes}

El vidrio $C$ (curva de transmisión en la Fig. 1) es un caso particular de los vidrios de color "en masa". Utilizando adecuadamente los componentes colorantes y las condiciones de fusión, se llega a un vidrio que manteniendo un valor de Transmisión Luminosa suficientemente elevado $\left(T_{L}>60 \%\right)$ tiene un valor relativamente bajo de Transmisión Energética $\left(T_{E} \sim 30 \%\right)$ debido a la fuerte banda de absorción que presenta en la zona del Infrarrojo solar.

Son vidrios de color con una buena funcionalidad respecto al confort climático y la protección solar.

Con los tipos de vidrios mostrados, obtenidos por modificaciones pequeñas en la composición de un vidrio "base" y el adecuado ajuste de las condicones de elaboración, puede hacerse una regulación selectiva de la radiación solar según el vidrio elegido. Mantener o atenuar la Transmisión Luminosa, la sensación del color, limitar aportaciones caloríficas al interior del edificio, son algunas de las posibilidades que ofrece la elección del vidrio adecuado. verres à haute transmission lumineuse et énergétique (pour e $<10 \mathrm{~mm}, T_{L} \approx 90 \%$ et FS $>0,8$ ).

Ce sont des verres qui facilitent les apports lumineux et énergétiques solaires.

Comme verre spécial de ce groupe, il faut mentionner le verre extra-blanc, dont la principale caractéristique est la transparence et la purété. II a été utilisé dans la Pyramide du Musée du Louvre, permettant l'emploi de plaques de 20 $\mathrm{mm}$. d'épaisseur $(10+10)$ sans altérer les nuances chromatiques de l'environnement et conférant à la construction une apparence légère. Ces verres, d'une absorption énergétique de l'ordre de $1 \%$ sont utilisés aussi pour des équipements de récupération et captation de l'énergie solaire.

\section{B) Verres absorbants "PARSOL"}

Il s'agit de verres très utilisés dans la construction dans la gamme de protection solaire. Ce sont des verres de couleur.

Dans ces verres, une partie très importante de la radiation solaire incidente ( $\propto 50 \%$ pour $6 \mathrm{~mm}$ d'épaisseur) est absorbée par le verre et postérieurement réemise sous la forme de IR aussi bien vers l'extérieur que vers l'intérieur dans des proportions qui dépendent des vitesses de l'air et des températures.

Les valeurs de $T_{L}$ et $F S$ (très variables avec l'épaisseur) sont indiquées sur la Table $V$.

\section{C) Verres fonctionnels très absorbants}

Le verre $C$ (courbe de transmission Fig. 1) est un cas particulier dans les verres colorés dans la masse. En utilisant d'une façon adéquate les composants colorants et les conditions de fusion, on obtient un verre qui maintient une valeur de Transmission Lumineuse suffisamment élevée, $\left(T_{L}>60 \%\right)$ mais avec une valeur de Transmission Energétique relativement faible $\left(T_{E} \approx 30 \%\right)$ par suite de la forte bande d'absorption presentée dans la zône de l'infrarouge solaire.

Il s'agit de verres de couleur avec une bonne fonctionnalité de confort climatique et de protection solaire.

Avec le type de verres montrés, obtenus au moyen de petites modifications dans la composition d'un verre de "base" et par l'ajustement appropié des conditions d'élaboration, on peut obtenir une régulation sélective de la radiation solaire. Le choix du verre adéquat nous permet de maintenir ou de diminuer la Transmission Lumineuse, la sensation de couleur et limiter les apports calorifiques à l'intérieur de l'édifice. 
TABLA V TABLE V

Características luminosas y energéticas (Caractéristiques lumineuses et énergétiques)

\begin{tabular}{|c|c|c|c|c|c|c|c|}
\hline \multirow[t]{2}{*}{$\begin{array}{l}\text { Producto } \\
\text { (Produit) }\end{array}$} & \multirow[t]{2}{*}{$\begin{array}{c}\text { Espesor } \\
\text { (Epaisseur) } \\
\mathrm{mm}\end{array}$} & \multicolumn{2}{|c|}{$\begin{array}{l}\text { Factores luminosos } \\
\text { (luz natural) } \\
\text { [Facteurs lumineux } \\
\text { (lumière solaire)] } \\
\mathbf{3 8 0 - 7 8 0 ~} \mathbf{n m}\end{array}$} & \multicolumn{3}{|c|}{$\begin{array}{c}\text { Factores energéticos (energía solar) } \\
\text { [Facteurs énergétiques (énergie solaire)] } \\
300-2.200 \mathrm{~nm}\end{array}$} & \multirow[t]{2}{*}{$\begin{array}{l}\text { Factor } \\
\text { solar } \\
\text { (Facteur } \\
\text { solaire) }\end{array}$} \\
\hline & & $\mathbf{R}_{\mathbf{L}}$ & $T_{L}$ & $\mathbf{R}$ & $\mathbf{A}$ & $\mathbf{T}$ & \\
\hline \multicolumn{8}{|c|}{ Lunas CRISTAÑOLA no absorbentes (Verres CRISTAÑOLA non absorbants) } \\
\hline PLANILUX & $\begin{array}{c}2 \\
3 \\
4 \\
5 \\
6 \\
8 \\
10 \\
15 \\
19\end{array}$ & $\begin{array}{l}0.08 \\
0.08 \\
0.08 \\
0.08 \\
0.08 \\
0.08 \\
0.08 \\
0.08 \\
0.08\end{array}$ & $\begin{array}{l}0.92 \\
0.91 \\
0.90 \\
0.90 \\
0.89 \\
0.89 \\
0.88 \\
0.83 \\
0.81\end{array}$ & $\begin{array}{l}0.07 \\
0.07 \\
0.07 \\
0.07 \\
0.07 \\
0.07 \\
0.07 \\
0.07 \\
0.07\end{array}$ & $\begin{array}{l}0.06 \\
0.06 \\
0.08 \\
0.09 \\
0.11 \\
0.15 \\
0.17 \\
0.21 \\
0.23\end{array}$ & $\begin{array}{l}0.87 \\
0.87 \\
0.85 \\
0.84 \\
0.82 \\
0.78 \\
0.76 \\
0.72 \\
0.70\end{array}$ & $\begin{array}{l}0.88 \\
0.88 \\
0.88 \\
0.87 \\
0.85 \\
0.82 \\
0.80 \\
0.79 \\
0.79\end{array}$ \\
\hline PINK-ROSA & $\begin{array}{c}4 \\
5 \\
6 \\
10\end{array}$ & $\begin{array}{l}0.06 \\
0.06 \\
0.06 \\
0.06\end{array}$ & $\begin{array}{l}0.75 \\
0.73 \\
0.70 \\
0.58\end{array}$ & $\begin{array}{l}0.06 \\
0.06 \\
0.06 \\
0.06\end{array}$ & $\begin{array}{l}0.17 \\
0.19 \\
0.22 \\
0.32\end{array}$ & $\begin{array}{l}0.77 \\
0.75 \\
0.72 \\
0.62\end{array}$ & $\begin{array}{l}0.81 \\
0.80 \\
0.78 \\
0.70\end{array}$ \\
\hline \multicolumn{8}{|c|}{ Lunas CRISTAÑOLA absorbentes (Verres CRISTAÑOLA absorbants) } \\
\hline $\begin{array}{l}\text { PARSOL } \\
\text { gris (gris) }\end{array}$ & $\begin{array}{c}4 \\
5 \\
6 \\
10\end{array}$ & $\begin{array}{l}0.05 \\
0.05 \\
0.05 \\
0.05\end{array}$ & $\begin{array}{l}0.56 \\
0.50 \\
0.44 \\
0.27\end{array}$ & $\begin{array}{l}0.05 \\
0.05 \\
0.05 \\
0.05\end{array}$ & $\begin{array}{l}0.35 \\
0.41 \\
0.46 \\
0.62\end{array}$ & $\begin{array}{l}0.60 \\
0.54 \\
0.49 \\
0.33\end{array}$ & $\begin{array}{l}0.69 \\
0.64 \\
0.60 \\
0.48\end{array}$ \\
\hline $\begin{array}{l}\text { PARSOL } \\
\text { bronce } \\
\text { (bronze) }\end{array}$ & $\begin{array}{c}4 \\
5 \\
6 \\
10\end{array}$ & $\begin{array}{l}0.05 \\
0.05 \\
0.05 \\
0.05\end{array}$ & $\begin{array}{l}0.61 \\
0.55 \\
0.50 \\
0.33\end{array}$ & $\begin{array}{l}0.05 \\
0.05 \\
0.05 \\
0.05\end{array}$ & $\begin{array}{l}0.36 \\
0.42 \\
0.48 \\
0.64\end{array}$ & $\begin{array}{l}0.59 \\
0.53 \\
0.47 \\
0.31\end{array}$ & $\begin{array}{l}0.68 \\
0.63 \\
0.59 \\
0.47\end{array}$ \\
\hline $\begin{array}{l}\text { PARSOL } \\
\text { verde (vert) }\end{array}$ & $\begin{array}{c}4 \\
5 \\
6 \\
10\end{array}$ & $\begin{array}{l}0.07 \\
0.07 \\
0.07 \\
0.07\end{array}$ & $\begin{array}{l}0.81 \\
0.77 \\
0.74 \\
0.64\end{array}$ & $\begin{array}{l}0.05 \\
0.05 \\
0.05 \\
0.05\end{array}$ & $\begin{array}{l}0.40 \\
0.46 \\
0.51 \\
0.63\end{array}$ & $\begin{array}{l}0.55 \\
0.49 \\
0.44 \\
0.32\end{array}$ & $\begin{array}{l}0.65 \\
0.61 \\
0.57 \\
0.48\end{array}$ \\
\hline
\end{tabular}

Cualquiera de estos vidrios se utiliza también como substrato para otras transformaciones (Acristalamientos aislantes, de seguridad, con capas metálicas reflectantes, etc. etc.) que pueden complementar o mejorar su funcionalidad.

\subsubsection{Vidrios con tratamientos superficiales}

Las modificaciones de la superficie del vidrio han permitido ampliar la gama de productos y prestaciones disponibles a partir de un único producto de base. Esta mayor disponibilidad y enriquecimiento de sus aportaciones, tanto estéticas como tecnológicas, han tenido un papel transcendente en la evolución de la construcción de edificios durante las últimas décadas. Al igual
N'importe lequel de ces verres est utilisé comme substrat pour d'autres transformations (Vitrages isolants, de sécurité, à couches métalliques refléchissantes, etc., etc.) qui peuvent compléter ou améliorer sa fonctionnalité.

\subsubsection{Verres à traitements superficiels}

Les modifications de la surface du verre nous permettent d'agrandir la gamme de produits et prestations disponibles à partir d'un seul produit de base. L'augmentation de la gamme d'utilisation et l'enrichissement des apports aussi bien esthétiques que technologiques ont joué un rôle très important dans l'évolution de la construction d'édifices pendant les dernières décennies. On a 
que en el vidrio, en la construcción la superficie (las fachadas) ha ganado importancia.

Son numerosos los tratamientos de superficie conocidos y empleados desde hace largo tiempo. En la tabla VI se recogen algunos de los más importantes, subrayando el último de ellos: "Depósitos en capa fina", que es, sin duda, el de máxima evolución en estos últimos años y sobre todo en el que se orientan numerosos trabajos actuales de investigación. Son muchos los nuevos productos que están surgiendo de las diferentes vías abordadas en este campo. Se tratarán con algún detalle en un apartado posterior.

Algunos de los productos, más utilizados en la construcción, obtenidos a partir de tratamientos de superficie (exceptuadas las capas finas) son:

\section{- Vidrios planos templados}

Frecuentemente, los acristalamientos de vidrio están sometidos a esfuerzos de flexión que se traducen en tensiones de compresión en una de sus caras y de tracción en la cara opuesta. Como ya es conocido, el vidrio tiene una buena resistencia a la compresión (similar a la del acero) y una resistencia peor a la tracción (10 veces inferior a la del acero). Como además es un material perfectamente elástico, cuando se le somete a una tensión de tracción suficientemente grande puede, en función del estado de superficie y de sus bordes, producirse la rotura sin dar lugar a una deformación previa.

Para aumentar la resistencia a la flexión hay varios procedimientos que consisten en poner sus dos caras en una fuerte compresión que augmenté la surface des façades vitrées dans la construction.

On connaît et on emploie beaucoup de traitements de surface depuis longtemps. Sur la Table VI on a enuméré certains de ces traitements en souligment le dernier: "Depôts en couche mince", qui est, sans doute, celui qui a subi la plus importante évolution durant ces dernières années et sur lequel on réalise actuellement de nombreux travaux de recherche. Les différentes voies suivies dans ce domaine ont fourni beaucoup de nouveaux produits. On en parlera avec plus de détail dans un prochain paragraphe.

Certains des produits, les plus utilisés dans la construction, obtenus à partir de traitements de surface (à l'exception des couches minces) sont:

\section{- Verres plats trempés}

Fréquemment, les vitrages sont soumis à des éfforts de flexion, traduits en tensions de compression sur une des faces et de contraintes d'extension sur la face opposée. Comme nous avons déjà vu le verre a une forte résistance à la compression (similaire à celle de l'acier) et une résistance moins bonne aux contraintes d'extension (10 fois inférieure à celle de l'acier). Comme il s'agit en plus d'un matériau parfaitement élastique, lorsqu'il est soumis à une tension de contrainte d'extension suffisamment grande il peut casser en fonction de l'état de surface et de ses bords, sans donner lieu à une déformation préalable.

II y a de différentes méthodes pour augmenter la résistance à la flexion. Il s'agit de soumettre les 2 faces à une forte compression poder compenser

TABLA VI TABLE VI

Tratamientos de superficie (Traitements de surface)

\begin{tabular}{|c|c|c|c|}
\hline \multirow{2}{*}{ Por extracción de materia } & Abrasión/mateado & \multirow{2}{*}{ Par extraction de matière } & Abrasion/depolissage \\
\hline & Ataque químico & & Attaque chimique \\
\hline Por modificación física & Temple & Par modification physique & Trempe \\
\hline \multirow{2}{*}{$\begin{array}{l}\text { Por modificación de la } \\
\text { estructura }\end{array}$} & $\begin{array}{l}\text { Efecto eléctrico/ } \\
\text { /desalcalinización }\end{array}$ & \multirow{2}{*}{$\begin{array}{l}\text { Par modification de } \\
\text { structure }\end{array}$} & $\begin{array}{l}\text { Eff. electrique/ } \\
\text { /désalcalinisation }\end{array}$ \\
\hline & $\begin{array}{l}\text { Desvitrificación/ } \\
\text { /ataque químico }\end{array}$ & & $\begin{array}{l}\text { Devitrification/ } \\
\text { /attaque chimique }\end{array}$ \\
\hline \multirow{2}{*}{$\begin{array}{l}\text { Por modificación de } \\
\text { composición }\end{array}$} & Cementación & \multirow{2}{*}{$\begin{array}{l}\text { Par modification de } \\
\text { composition }\end{array}$} & Cémentation \\
\hline & $\begin{array}{l}\text { Intercambio iónico/ } \\
\text { /temple químico }\end{array}$ & & $\begin{array}{l}\text { Échange ionique/ } \\
\text { /trempe chimique }\end{array}$ \\
\hline Por depósito de materia & Capas finas & Par dépot de matière & Couches minces \\
\hline
\end{tabular}


compense las tracciones que se pueden originar durante su uso:

\section{- Temple térmico}

Se calienta el vidrio, previamente cortado a la dimensión de utilización, hasta temperaturas del orden de los $700^{\circ} \mathrm{C}$ y se enfrían bruscamente las superficies de la hoja. Éstas se "fijan" antes que la parte central. Cuando ésta se enfría, se contrae y somete a una compresión permanente a una fina capa de las superficies.

Se aumenta así considerablemente la resistencia a la flexión (5 a 10 veces superior al vidrio no templado). Además tiene otros efectos inducidos como: Un incremento notable de la resistencia al choque térmico y una fragmentación en pequeños trozos que hacen mucho menos peligrosas las roturas.

Su uso, muy extendido hace algunos años en fachadas, puertas interiores, etc., está siendo desplazado por los productos compuestos (tipo STADIP) de máxima seguridad.

Este procedimiento de refuerzo se utiliza por prescripción en aquellos vidrios que por su elevada absorción energética pueden tener riesgos de rotura por choque térmico.

\section{- Temple químico}

Mediante el intercambio iónico en la superficie (sustitución de iones de Sodio por iones más grandes de Potasio), con un tratamiento de inmersión del vidrio en sales fundidas a determinada temperatura, se consigue también crear esfuerzos de compresión en las caras del vidrio.

El proceso es más complejo que el anterior y los tiempos de tratamiento mucho más largos para obtener espesores en compresión suficientes (> $50 \mu \mathrm{m}$ ).

Las compresiones que se consiguen son muy elevadas llegando los vidrios a resistencias a la flexión del órden de los $10.000 \mathrm{~kg} / \mathrm{cm}^{2}$.

Se utilizan estos vidrios en aplicaciones muy especiales y cuando se desea reforzar vidrios muy delgados.

\subsubsection{Vidrios planos con capas superficiales}

Durante los últimos 10 años se ha desarrollado de forma espectacular la aplicación de capas sobre el vidrio. Teniendo en cuenta los diferentes procedimientos de aplicación, los diversos componentes de la capa, los numerosos substratos posibles y combinaciones de éstos, el número de productos que ya existe sobre el les contraintes d'extension appliquées pendant son utilisation:

\section{- Trempe thermique}

On chauffe le verre, préalablement coupé à la dimension d'utilisation, jusqu'à des températures d'environ $700^{\circ} \mathrm{C}$ puis on refroidit brusquement les surfaces de la feuille. Elles sont "fiées" avant le coeur. Quand celui-ci se réfroidit, il se contracte, et il en résulte une compression permanente dans une faible épaisseur de chacune des faces.

On augmente ainsi, considérablement, la résistance à la flexion (5 à 10 fois supérieur au verre non trempé). II y a en plus d'autres effects induits comme: Une importante augmentation de la résistance au choc thermique et une fragmentation en petits morceaux qui rend les cassures moins dangereuses.

Il était très utilisé il y a quelques années sur les façades, portes intérieures, etc. mais actuellement il a été remplacé par les produits composés (type STADIP) de sécurité maximale.

Ce procédé de renforcement s'utilise, par prescriptions surtes vitrages à forte absorption énergétique qui pourraient présenter des risques de casse par chocs thermiques.

\section{- Trempe chimique}

Au moyen d'un échange ionique sur la surface (remplacement de ions de Sodium par ions plus grands de Potassium), par traitement d'immersion du verre à une température déterminée dans des sels fondus, on peut aussi créer des forces de compression sur les faces du verre.

Ce procédé est plus complèxe que le précédent et les temps de traitement sont beaucoup plus longs pour obtenir des épaisseurs en compression suffisantes (>50 $\mu \mathrm{m})$.

Les compressions obtenues sont très élevées, conférant aux verres des résistances à la flexion de l'ordre des $10.000 \mathrm{~kg} / \mathrm{cm}^{2}$.

Ces verres sont utilisés pour des applications très spéciales et lorsque l'on désire renforcer des verres très minces.

\subsubsection{Verres plats avec couches de surface}

Au cours de ces dix dernières années on a développé d'une façon spectaculaire l'application de couches sur le verre. Compte tenu des différents procédés d'application, des différents composants de la couche des nombreux substrats possibles et combinaisons de ceux-ci, le nombre de produits déjà existants dans le marché, et ceux 
mercado, y los que continuamente aparecen fruto de las investigaciones y desarrollos en curso, es tan importante y tan extendido su uso, que puede decirse que con las capas se ha iniciado una nueva $\theta$ innovadora etapa del vidrio en la construcción.

Volviendo al esquema de la tabla II, estos vidrios cubren de forma selectiva la funcionalidad para la que han sido diseñados:

- Contribuyen de forma total a la estética y diseño del edificio. Asociados a los muroscortina, sistemas Structural Glazing, etc., dando lugar a las fachadas todo-vidrio, más o menos reflectantes y con colores diversos, han contribuido a realzar los efectos de volúmenes y superficies a la vez que la singularidad de cada edificio, aspectos fundamentales en la arquitectura.

- Resuelven directamente los problemas de confort térmico regulando a la vez y selectivamente la transmisión luminosa y los aportes (o en otros casos pérdidas) energéticas a través del acristalamiento.

- Aportan nuevas funciones al vidrio y son base de productos más complejos:

V. electrocrómicos; V. con cristales líquidos; etc.

De forma general, las capas aplicadas sobre un substrato de vidrio convencional pueden aportar modificaciones en sus propiedades:

\section{- Espectrofotométricas:}

- Transmisión luminosa/Transmisión enérgética/Factor solar.

- Color (Por transmisión y por reflexión).

- Reflexión selectiva $\left(R_{L} / R_{E} / R_{I R}\right)$.

- Eléctricas:

- Conductividad de superficies/Fotovoltaismo.

- Térmicas:

- Variación de FS (consecuencia de las anteriores).

- Transmisión de calor (modificación de la emisividad).

La modificación de las propiedades ópticas del vidrio en las regiones espectrales definidas por la radiación solar y por el IR lejano (característica de las emisiones de materiales y calefacción del interior de los edificios), define las principales funciones aportadas por las capas finas. De qui apparaissent constamment fruit de l'effort de recherche et développement en cours, on peut assurer qu'avec les couches, une nouvelle étape d'innovation est commencée pour la construction.

Revenons sur le schéma de la Table II, ces verres couvrent d'une façon sélective la fonction pour laquelle ils ont été destinés.

- Contribution à l'esthetique et dessin de l'edifice. Associés aux murs-rideaux,systèmes Structural Glazing, etc., ils permettent de construire les façades tout-verre, plus ou moins réfléchissantes et de couleurs différents, en contribuant aussi à mettre en relief les effets des volumes et surfaces et donnant en plus un caractère particulier à chaque bâtiment, aspect fondamental dans l'architecture.

- Ils résolvent directement les problèmes de confort thermique en régulant à la fois et sélectivement la transmission lumineuse et les apports (ou pertes dans d'autres cas) énergétiques au moyen du vitrage.

- Ils apportent de nouvelles propriétés au verre et constituent la base de produits complèxes: verres electrochromes; verres a cristaus liquides; etc.

En général, les couches appliquées, sur le substrat de verre conventionnel peuvent apporter des modifications dans ses propriétés:

\section{- Spectrophotométriques.}

- Transmission lumineuse/Transmission énergétique/Facteur solaire.

- Couleur (par transmission et réflexion).

- Réflexion sélective $\left(R_{L} / R_{E} / R_{I R}\right)$.

- Electriques.

- Conductivité de sufrace/Photovoltaisme.

- Thermiques.

- Variation du FS (conséquence des precédentes).

- Transmission de la chaleur (modification de l'émissivité).

La modification des propriétés optiques du verre dans les régions spectrales définies par la radiation solaire et par l'IR lointain (caractéristique des émissions de matériaux et chauffage de l'intérieur des bâtiments), definit les principales fonctions apportées par les couches minces. Dans 
TABLA VII

Funcionalidad del vidrio con capas

\begin{tabular}{|c|c|c|c|}
\hline \multicolumn{2}{|c|}{ Región espectral } & $\begin{array}{l}\text { Propiedad modificada } \\
\text { por la capa }\end{array}$ & $\begin{array}{l}\text { Función del vidrio } \\
\text { con capa }\end{array}$ \\
\hline \multirow{5}{*}{\multicolumn{2}{|c|}{ Visible $(0,42$ a $0,72 \mu \mathrm{m})$}} & \multirow{2}{*}{ Color } & Estética \\
\hline & & & $\begin{array}{l}\text { Sustitución de la coloración } \\
\text { del vidrio en masa }\end{array}$ \\
\hline & & \multirow{2}{*}{ Reflexión aumentada } & $\begin{array}{l}\text { Confort en verano } \\
\text { (construcción) }\end{array}$ \\
\hline & & & $\begin{array}{l}\text { Economías de } \\
\text { climatización }\end{array}$ \\
\hline & & Reflexión disminuida & Estética (anti-reflejo) \\
\hline \multirow{3}{*}{ Solar $(0,3$ a $2,2 \mu \mathrm{m})$} & \multirow{2}{*}{$\begin{array}{l}\text { Infrarrojo solar } \\
(0,7 \text { a } 2,2 \mu \mathrm{m})\end{array}$} & \multirow{2}{*}{ Reflexión aumentada } & $\begin{array}{l}\text { Confort en verano } \\
\text { (construcción, automóvil) }\end{array}$ \\
\hline & & & $\begin{array}{l}\text { Economías de } \\
\text { climatización }\end{array}$ \\
\hline & $\begin{array}{l}\text { Ultravioleta } \\
(0,3 \text { a } 0,42 \mu \mathrm{m})\end{array}$ & Transmisión disminuida & $\begin{array}{l}\text { Antidecoloración } \\
\text { (protección de los objetos } \\
\text { expuestos en vitrinas, } \\
\text { obras de arte...) }\end{array}$ \\
\hline \multicolumn{2}{|c|}{ Infrarrojo lejano (centrado a unas $13,5 \mu \mathrm{m}$ ) } & Reflexión aumentada & Economías de calefacción \\
\hline
\end{tabular}

TABLE VII

(Fontionnalisme du verre à couches)

\begin{tabular}{|c|c|c|c|}
\hline \multicolumn{2}{|c|}{ Region spectrale } & $\begin{array}{l}\text { Propriété modifiée } \\
\text { par la couche }\end{array}$ & $\begin{array}{l}\text { Fonction du verre } \\
\text { avec la couche }\end{array}$ \\
\hline \multirow{5}{*}{\multicolumn{2}{|c|}{ Visible $(0,42$ à $0,72 \mu \mathrm{m})$}} & \multirow{2}{*}{ Couleur } & Esthétique \\
\hline & & & $\begin{array}{l}\text { Substitution de la coloration } \\
\text { du verre dans la mase }\end{array}$ \\
\hline & & \multirow{2}{*}{ Réflection augmentée } & $\begin{array}{l}\text { Confort en été } \\
\text { (construction) }\end{array}$ \\
\hline & & & Economies de climatization \\
\hline & & Réflection diminuée & Esthétique (antireflet) \\
\hline \multirow{3}{*}{ Solaire $(0,3$ á $2,2 \mu \mathrm{m})$} & \multirow{2}{*}{$\begin{array}{l}\text { Infrarouge solaire } \\
(0,7 \text { à } 2,2 \mu \mathrm{m})\end{array}$} & \multirow{2}{*}{ Réflection augmentée } & $\begin{array}{l}\text { Confort en été } \\
\text { (construction, automobile) }\end{array}$ \\
\hline & & & Economies de climatisation \\
\hline & $\begin{array}{l}\text { Ultraviolet } \\
(0,3 \text { à } 0,42 \mu \mathrm{m})\end{array}$ & Transmission diminuée & $\begin{array}{l}\text { Antidécoloration (protection } \\
\text { des objets exposés en } \\
\text { vitrine, objets d'art, ...) }\end{array}$ \\
\hline \multicolumn{2}{|c|}{ Infrarouge lointain (centré sur $13,5 \mu \mathrm{m}$ ) } & Réflection augmentée & Economies de chauffage \\
\hline
\end{tabular}


manera muy esquemática y simplificada, en la tabla VII, se resumen las propiedades modificadas y la funcionalidad obtenida.

Se consigue así una extensa gama de productos:

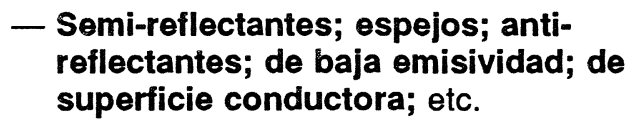

Ante los numerosos productos existentes con funciones parecidas, solamente el proceso de depósito y los materiales que se depositan (características de cada fabricante) definen y diferencian unas capas de otras.

A continuación se hace una breve descripción de los diferentes procedimientos utilizados acompañado de algún ejemplo de los productos obtenidos y sus usos más frecuentes:

\section{- Depósitos químicos}

Por reacción química sobre el substrato. Se obtienen capas metálicas, generalmente poco resistentes por su débil adhesión al soporte.

Es un procedimiento antiguo cuyo empleo actual está prácticamente limitado a la fabricación de "ESPEJOS" (Dos capas metálicas de Ag y Cu protegidas por pinturas orgánicas). Su uso es bien conocido, sobre todo, en decoración e interiores.

\section{- Depósitos por pirólisis}

Se trata, en cualquier caso, de una descomposición a elevadas temperaturas (prox. a $600^{\circ} \mathrm{C}$ ) de componentes químicos que reaccionan dando lugar a nuevos compuestos que se integran en forma de capa fina y homogénea sobre la superficie del vidrio.

La ventaja de estos depósitos es que al incorporarse sobre el vidrio a elevadas temperaturas su adherencia es muy buena (por reacciones entre el propio vidrio y los componentes constitutivos de la capa en las superficies límite de contacto). Además de esta importante ventaja, que mejora la resistencia mecánica de las capas, normalmente, estos depósitos se realizan en continuo, directamente sobre la línea de fabricación del vidrio, con elevadas cadencias de producción y relativos bajos costes.

En los depósitos por pirólisis se establece una diferencia en función del estado de los componentes aportados:

\section{- Pirólisis en fase vapor (CVD)}

la Table VII on a résumé, de façon schématique et simplifiée, les propriétés modifiées et la propriété obtenue.

On arrive ainsi à obtenir une large gamme de produits:

\section{- Semi-reflechissants; miroirs; antireflechissants; de faible emissivite; de surface conductrice, etc.}

D'après les nombreux produits existants avec des fonctions similaires, seule le procédé de dépôt et les matériaux déposés (caractéristiques de chaque fabricant) peuvent definir et différentier les couches entre elles.

Ci-après nous faisons une brève description des différents procédés utilisés, accompagnée de quelques exemples des produits obtenus et de ses de plus fréquents usages:

\section{- Dépóts chimiques}

Par réaction chimique sur le substrat. On obtient des couches métalliques, peu résistantes en général par suite de leur faible adhésion au support.

II s'agit d'un procédé ancien, et actuellement il ne s'emploie que pour la fabrication de "MIROIRS" (2 couches métalliques de Ag et Cu protégées par peintures organiques). II s'utilise surtout pour la décoration et les intérieurs.

\section{- Dépóts par pyrolyse}

Il s'agit, dans tous les cas, d'une décomposition à températures élevées (proches de $600^{\circ} \mathrm{C}$ ) de composants chimiques qui sont intégrés sous la forme d'une couche mince et homogène sur la surface du verre.

Ces dépôts ont un avantage, l'incorporation au verre à des températures élevées qui donne une très bonne adhérence (par suite des réactions entre le verre lui même et les composants qui constituent la couche dans les surfaces limites de contact). En plus de cet important avantage, qui améliore la résistance mécanique des couches, normalement ces dépôts sont réalisés en continu, directement sur la ligne de fabrication du verre, avec des cadences élevées de production et des coûts relativement bas.

Entre les dépots par pyrolyse il y a une différence en fonction de l'état des composants apportés:

\section{- Pyrolyse en phase vapeur (CDV)}


Los componentes de pirólisis, originalmente en estado gaseoso o gasificados previamente, se hacen entrar en contacto con la superficie caliente del vidrio mediante un dispositivo especial.

El único problema de este procedimiento es que la velocidad de formación de la capa es pequeña y esto limita la velocidad de circulación del vidrio (para fabricación en línea continua).

Un ejemplo característico son los vidrios tipo "REFLECTASOL".

El componente principal utilizado es gas Silano $\left(\mathrm{Si} \mathrm{H}_{4}\right)$, que se descompone por encima de los $400^{\circ} \mathrm{C}$, sin la presencia de oxígeno, dejando libre el Silicio elemental que se deposita sobre el vidrio formando la capa.

Se aprovechan así las condiciones favorables del baño "Float" (de la fabricación de vidrio plano): temperaturas de aproximadamente $600^{\circ} \mathrm{C}$; atmósfera reductora; condiciones de marcha bien controladas; etc.

Es un producto anti-solar (tiene una alta reflexión luminosa y energética solar) con especiales aplicaciones en climas cálidos y lugares muy soleados. Su factor solar es próxima al $50 \%$ (tabla VIII).

Esta capa resiste bien la manufactura, temple, ensamblado en dobles acristalamientos, laminares, etc.

\section{- Pirólisis en fase líquida}

Se trata de proyectar una suspensión o solución, sobre el vidrio caliente, con un portador en estado líquido.

Los precursores más frecuentes son las soluciones en un disolvente adecuado de compuestos organometálicos de $\mathrm{Cr}, \mathrm{Co}, \mathrm{Ni}, \mathrm{Fe}, \ldots$
Les composants de pyrolyse, en état gazeux à l'origine ou gazéifiés préalablement, entrent en contact avec la surface chaude du verre au moyen d'un dispositif spécial.

Le seul problème de ce procédé est la vitesse de formation de la couche qui est petite et ceci limite la vitesse de circulation du verre (pour fabrication en ligne continue).

Un exemple caractéristique de ces verres est le verre type "REFLECTASOL".

Le principal composant utilisé est le gaz Silane (Si $\left.\mathrm{H}_{4}\right)$, qui se décompose au dessus de $400^{\circ} \mathrm{C}$ sans la présence d'oxygène, en laissant libre le Silicium élementaire déposé sur le verre en formant la couche.

On profite aussi des conditions favorables du bain "Float" (de la fabrication de verre plat): températures d'environ $600^{\circ} \mathrm{C}$; atmosphère réductrice; conditions de marche bien controlées; etc.

C'est un produit anti-solaire (réflexion lumineuse et énergétique solaire élevées). II est utilisé surtout sous les climats chauds et les lieux exposés au soleil. Son facteur solaire est proche au $50 \%$ (V. Table VIII).

Cette couche supporte bien la manutention, la trempe, l'assemblage en double vitrage, le feuilletage, etc.

\section{- Pyrolyse en phase liquide}

II s'agit de projeter une suspension ou une solution sur un verre chaud, avec un porteur à l'etat liquide.

Fréquemment les précurseurs sont les solutions de composés organométalliques de $\mathrm{Cr}$, Co, $\mathrm{Ni}$, $\mathrm{Fe}$, ... dans un solvant approprié. Ils sont

TABLA VIII TABLE VIII

\begin{tabular}{|c|c|c|c|c|c|c|}
\hline \multirow{2}{*}{$\begin{array}{l}\text { Producto } \\
\text { (Produit) }\end{array}$} & \multirow{2}{*}{$\begin{array}{l}\text { Espesor } \\
\text { (Epaisseur) } \\
(\mathrm{mm})\end{array}$} & \multicolumn{2}{|c|}{$\begin{array}{l}\text { Factores luminosos } \\
\text { (luz natural) } \\
\text { [Facteurs lumineux } \\
\text { (lumière naturelle)] }\end{array}$} & \multicolumn{2}{|c|}{$\begin{array}{l}\text { Factores energéticos } \\
\text { (energía solar) } \\
\text { [Facteurs énergétiques } \\
\text { (énergie solaire)] }\end{array}$} & \multirow{2}{*}{$\begin{array}{l}\text { Factor } \\
\text { solar } \\
\text { (Facteur } \\
\text { solaire) }\end{array}$} \\
\hline & & $\begin{array}{l}\text { Reflexión } \\
\text { (Réflexion) }\end{array}$ & $\begin{array}{l}\text { Tranmisión } \\
\text { (Transmis.) }\end{array}$ & $\begin{array}{l}\text { Reflexión } \\
\text { (Réflexion) }\end{array}$ & $\begin{array}{l}\text { Tranmisión } \\
\text { (Transmis.) }\end{array}$ & \\
\hline REFLECTASOL & 6 & 0,51 & 0,33 & 0,36 & 0,45 & 0,51 \\
\hline CLIMALIT $\left({ }^{*}\right)$ & 18 & 0,51 & 0,29 & 0,38 & 0,34 & 0,43 \\
\hline PLANILUX & 6 & 0,08 & 0,89 & 0,07 & 0,82 & 0,85 \\
\hline
\end{tabular}

(*) Acristalamiento aislante CLIMALIT.-Composición: REFLECTASOL $6 \mathrm{~mm}+$ cámara de aire $6 \mathrm{~mm}+$ PLANILUX $4 \mathrm{~mm}$. (Vitrage isolant CLIMALIT. - Composition: REFLECTASOL $6 \mathrm{~mm}+$ lame d'air $6 \mathrm{~mm}+$ PLANILUX $4 \mathrm{~mm}$ ). 
Se aplican con un sistema de proyectores directamente sobre la hoja de vidrio caliente en la propia línea de fabricación. La descomposición de estos compuestos deja depositados sobre el vidrio los diferentes óxidos metálicos responsables de las propiedades de la capa.

Este procedimiento proporciona capas de muy buena resistencia química y mecánica, y suficientemente duras y estables para permitir tratamientos posteriores: temple, curvado, esmaltado, etc.

Se producen así los vidrios tipo "ANTELIO", también de características anti-solares $\left(R_{L}=0,34\right.$, $R_{E}=0,28$ y $F S=55 \%$ ).

Tanto en fase vapor como líquida se pueden fabricar también capas de otras características, como las electroconductoras (p. ej.).

\section{— Pirólisis en fase solida}

Procedimiento y tecnología desarrollada por SAINT GOBAIN para la fabricación de capa "EKO". Consiste en proyectar sobre el vidrio caliente, mediante un sistema de distribución lineal, un flujo gaseoso portador de los granos finamente divididos (50 $\AA$ ) del compuesto reactivo. Por descomposición pirolítica se forma sobre el vidrio una capa de un semi-conductor transparente $\left(\mathrm{SnO}_{2}\right)$ dopado con fluor $(F)$.

Con la introducción del dopante $(F)$ se baja la resistividad del $\mathrm{SnO}_{2}$. El elevado contenido de portadores de carga asociado a su gran movilidad hace que estas capas presenten una conductividad metálica lo que equivale a una elevada reflexión en el Infrarrojo. Son capas de baja emisividad.

La CAPA "EKO" se obtiene en la misma línea de fabricación del vidrio soporte, es decir, en anchura de 3,2 m, sobre vidrio de varios espesores y en marcha continua (a velocidad de hasta $20 \mathrm{~m} / \mathrm{min}$ ).

Es una capa transparente. Deja pasar la mayor parte de la energía solar (Tiene un Factor Solar de $\approx 74 \%$ ya instalada en un doble acristalamiento). Presenta un color ligeramente azul por reflexión desde el exterior y es neutro por transmisión desde el interior. Su propiedad más importante es reflejar la radiación infrarroja emitida desde el interior del edificio, es decir, reducir las pérdidas caloríficas por el acristalamiento (el coef. de transmisión térmica $K$ de un D.A. se reduce en un $30 \%$ ) y disminuir el efecto de "pared fría". Es un producto dirigido al confort térmico y las economías de energía.

Es una capa de muy buena resistencia a la abrasión, a la corrosión del ambiente y soporta appliqués avec un système de projection directement sur la feuille de verre chaud sur la ligne de fabrication elle même. La décomposition de ces composés dépose sur le verre les différents oxydes métalliques responsables des propriétés de la couche.

Ce procédé délivre des couches de trés bonne résistance chimique et mécanique et suffisamment dures et stables, ce qui autorise des traitements postérieurs: trempe, courbure, émaillage ...

On fabrique ainsi les verres type "ANTELIO" qui possèdent aussi des caractéristiques anti-solaires $\left(R_{L}=0,34, R_{E}=0,28\right.$ et $\left.F S=55 \%\right)$.

On peut fabriquer aussi en phase vapeur ou liquide des couches avec d'autres caractéristiques: p.ex., les électroconductrices.

\section{- Pyrolyse en phase solide}

Procédé et technologie développé par Saint Gobain pour la fabrication de couches "EKO". II s'agit de projeter sur le verre chaud, au moyen d'un système de distribution linéaire, un flux gazeux porteur des grains divisés très fins (50 A) du composé réactif. Une couche de semiconducteur transparent $\left(\mathrm{SnO}_{2}\right)$ dopée avec fluor (F) est formée sur le verre par décomposition pyrolytique.

Avec l'introduction du dopant $(F)$ la résistivité du $\mathrm{SnO}_{2}$ diminue. L'elevé contenu des porteurs de charge ainsi que leur grande mobilité font que ces couches présentent une conductivité métallique, ce qui revient à dire une élevée réflexion dans l'Infrarouge. II s'agit de couches à faible émissivitée.

La couche "EKO" s'obtient dans la même ligne de fabrication du verre support, c'est à dire, largeur 3,2 m, sur verre de différentes épaisseurs et en marche continue (vitesse de jusqu'a $20 \mathrm{~m} / \mathrm{min}$.).

Elle est une couche transparente. Elle permet de passer une grande partie de l'énergie solaire (ayant un Facteur Solaire de $74 \%$ installé sur double vitrage). La coloration du verre à couches EKO vu par réflexion de l'extérieur est légèrement bleuâtre, tandis qu'observé par transmission a une coloration neutre. Sa plus importante propriété est la réflexion de la radiation infrarouge émise de l'intérieur du bâtiment, c'est à dire, réduire les pertes calorifiques par le vitrage (réduction de $30 \%$ coef. transmission thermique $K$ d'un D.V.) et diminution de l'effet de "paroifroid". II s'agit d'un produit adressé au confort thermique et les economies d'energie.

II s'agit d'une couche très résistante à l'abrasion, à la corrosion de l'ambience et supporte 
perfectamente el envejecimiento. En España se comercializa formando parte de un doble acristalamiento (el CLIMALIT PLUS).

\section{- Depósitos superficiales bajo vacio}

Este tipo de capas finas, con un importante desarrollo actual, están marcando una nueva época en el arte de construir. La extensa gama de productos realizable con estas tecnologías permite personalizar cada edificio con la combinación elegida de colores y reflexiones, a la vez que se le dota del confort luminoso y térmico deseado. La combinación con otros productos de vidrio puede añadirle el resto de funciones como la seguridad.

De forma general, estos procedimientos de obtención de capas consisten en:

- Transformar el material a depositar en vapor dentro de una cámara de vacío.

- Orientar y transferir este vapor al vidrio.

- Condensarle sobre la superficie del vidrio formando una capa final.

Son especialmente adecuados para depositar metales y aleaciones de éstos, pero con los desarrollos más modernos de esta tecnología también se pueden depositar óxidos, carburos, nitruros, etc. y formar diversos apilamientos de capas.

El vapor del material a depositar se produce por dos técnicas diferentes: evaporización y pulverización.

- Evaporización. Mediante el calentamiento del material a depositar (ej. Joule, inducción, bombardeo electrónico, ...) dentro de una cámara de vacío o bajo atmósfera inerte a muy baja presión. Las moléculas de vapor se propagan hasta encontrar el substrato (vidrio) donde se condensan. parfaitement le vieillissement. En Espagne elle est commercialisée en formant un tout avec le double vitrage (CLIMALIT PLUS).

\section{- Depots superficiels sous vide}

Ce type de couches fines, avec un développement très important actuellement, est en train de marquer une nouvelle époque dans l'art de construire. La grande diversité de produits réalisables avec ces technoloigies permet de personnaliser chaque bâtiment avec la combinaison choisie de couleurs et réflexions, avec le confort lumineux et thermique souhaité. La combinaison avec d'autres produits de verre peut ajouter des fonctions comme la sécurité.

De façon générale, ces procédés d'obtention de couches consistent en:

- Transformation du matériau à déposer en vapeur dans une chambre à vide.

- Orientation et transfert de cette vapeur au verre.

- Condensation sur la surface du verre en formant une couche finale.

Ils sont spécialement adéquats pour déposer des métaux ou ses alliages, mais les développements les plus modernes de cette technologie permettent de déposer aussi des oxydes, carbures, nitrures, etc. et former des différents empilements de couches.

La vapeur du matériau à déposer est produite par deux techniques différentes: Vaporisation et Pulvérisation.

- Vaporisation. En rechauffant le matériau à déposer (ex., Joule, induction, bombardement électronique, ...) dans une chambre à vide ou faible atmosphère inerte à très basse pression. Les molécules de vapeur se répandissent jusqu'a rencontrer le substrat (verre) où elles se condensent.

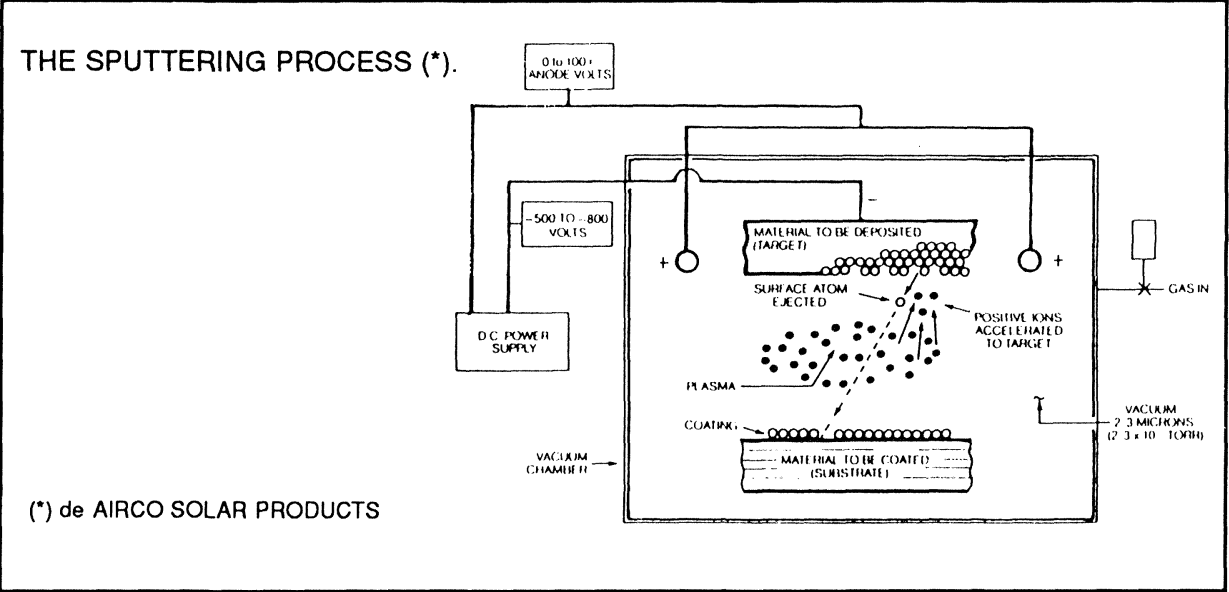

Fig. 3 
- Pulverización catódica (Sputtering). El vapor es obtenido por bombardeo de partículas de un gas, parcialmente ionizado, sobre el cátodo del material a depositar, arrancando átomos de éste que se proyectan sobre el substrato.

La descarga de los iones positivos del gas produce electrodos secundarios que vuelven a entrar en colisión con los átomos del gas ionizado de nuevo, dando continuidad al ciclo.

- Pulverización catódica con magnetrón. Con el mismo principio de la anterior su particularidad (Fig. 3) es la superposición sobre el cátodo de un campo magnético que permite confinar próximos a la diana a los electrodos secundarios, aumentando así el rendimiento de la reacción de ionización del gas. Se incrementa así la velocidad de depósito. Es, sin duda, el sistema más utilizado actualmente.

- Pulverización reactiva. Se incorpora al anterior y permite los depósitos de compuestos di-atómicos estables por reacción del catódo con un gas previamente elegido (Se forman así las capas de óxidos, carburos, nitruros, etc.)

Con la tecnología descrita, utilizada por los fabricantes de vidrio plano, se abre un campo espectacular a la innovación en la construcción. El número de productos disponibles es muy elevado y continuamente se fabrican otros nuevos en función de la demanda.

En general, los productos comercializados consisten en una o varias capas finas de metales ( $\mathrm{Au}, \mathrm{Ag}, \mathrm{Cr}, \mathrm{Ti}, \mathrm{Zn}, \mathrm{Sn}, \mathrm{Cu}, \mathrm{Ac}$. inox. etc.) $\mathrm{y} / \mathrm{u}$ óxidos metálicos, depositados sobre un vidrio (substrato) incoloro o de color. Se puede disponer así de vidrio con una elevada gama de colores y variantes en las $T_{L}, T_{E}, R_{L}, F_{S}, E, \ldots$

Solamente en el catálogo de los "COOL-LITE" existen 14 colores diferentes, con 46 referencias diferenciadas por el aspecto y por sus características luminosas y energéticas.

En el propio Grupo SAINT GOBAIN se sigue un importante programa de investigación para la obtención de multicapas que tengan un buen compromiso entre la transmisión luminosa deseada, un factor solar bajo y la coloración y reflexión exterior elegida.

Una particularidad de esta familia de productos son los dotados de capas de baja emisividad (Low-E). Son multicapas tipo "PLANITHERM" (Ox. de estaño/plata/ox. de estaño) con un coef. de emisividad $(E \propto 0,1)$ y una Transmisión luminosa elevada $\left(T_{L} \approx 80 \%\right)$ en vidrio monolítico de $e=4$ $\mathrm{mm}$.
- Pulverisation cathodique (sputtering). La vapeur est obtenue par bombardement de particules d'un gaz, partiellement ionisé, sur le cathode du matériau à déposer, en dégageant des atomes de celui-ci qui sont projetés sur le substrat.

La décharge des ions positifs du gaz produit des électrodes secondaires qui rentrent à nouveau en colision avec les atomes du gaz ionisé une autre fois, continuant le cycle.

- Pulverisation cathodique avec magnetron. Avec le même principe que l'antérieure, mais sa particulaité (Fig. 3) est la superposition d'un champ magnétique sur le cathode, permettant de confiner les électrodes secondaires proches à la diane, en augmentant ainsi le rendement de la réaction de ionisation du gaz. De cette façon la vitesse de dépôt augmente. II s'agit, sans doute, du système le plus utilisé actuellement.

- Pulverisation reactive. Elle est incorporée à l'antérieure et permet les dépôts de composés di-atomiques stables par réaction du cathode avec un gaz préalablement choisi. (On forme ainsi les couches d'oxydes, carbures, nitrures, etc).

Avec cette technologie décrite, utilisée par les fabricants de verre plat, on ouvre un champ spectaculaire à l'innovation dans la construction. Le nombre de produits disponibles est très élevé et on fabrique de façon continue d'autres produits nouveaux en fonction de la demande.

En général, les produits commercialisés consistent en une ou plusieurs couches fines de métaux (Au, Ag, Cr, Ti, Zn, Sn, Cu, Ac.Inox, etc.) et/ou oxydes métalliques, déposés sur.un verre (substrat) clair ou de couleur. On dispose alors de verre à une elevée gamme de couleurs et variantes dans les $T_{L}, T_{E}, R_{L}, F_{S}, E, \ldots$

Dans le catalogue des "COOL-LITE" il y a 14 couleurs différentes, avec 46 réferences différentes d'après l'aspect et les caractéristiques lumineuses et énergétiques.

Dans le Groupe SAINT GOBAIN il existe un important programme de recherche pour l'obtention de multicouches ayant un bon engagement entre la transmission lumineuse souhaitée, un facteur solaire bas et la coloration et la réflexion extérieure choisies.

Une particularité de cette famille sont les produits à couches de faible émissiveté (Low-E). II s'agit de multicouches type "PLANITHERM" (Ox. d'etain/argent/Ox.d'etain) avec un coefficient d'émissivité $(E \propto 0,1)$ et une Transmission Lumineuse élevée $\left(T_{L} \propto 80 \%\right)$ en verre monolithique $\theta=4 \mathrm{~mm}$. 
Son productos dirigidos a limitar las pérdidas energéticas por los acristalamientos.

Como resumen, con esta importante familia de nuevos vidrios funcionales, la elección del vidrio soporte, la capa y la composición o producto final de montaje en el edificio, se pueden conseguir:

- VIDRIOS DE COLOR ANTISOLARES. Con fuerte reflexión en el visible y en el IR solar (Baja Transmisión luminosa y Factor Solar).

\section{- VIDRIOS NEUTROS ANTISOLARES. Bajas reflexión y absorción en el visible (INCOLOROS) y alta reflexión en el IR solar (bajo FS).}

- VIDRIOS NEUTROS NO-EMISIVOS (Low-E). Permiten el paso de la energía solar (luz y calor) y reflejan el IR lejano. Facilitan las aportaciones solares y aumentan el aislamiento.

Y los compromisos y combinaciones entre todos ellos, que permiten resolver la mayor parte de las exigencias de estética, confort y economías de energía en la edificación moderna.

\section{- Capas por sol-gel}

Es una vía que, aunque poco utilizada aún a nivel industrial, tiene un importante futuro para los depósitos o capas de propiedades selectivas. Conceptualmente y a nivel de Laboratorio tiene pocas limitaciones en cuanto a la naturaleza de las capas o la pureza de éstas.

Esencialmente, aunque existen varios procesos diferentes, consiste en partir de una solución -Solque contiene sílice coloidal en suspensión y los demás componentes de la capa en disolución. Inmersión del vidrio a recubrir y extracción a velocidad controlada para ajustar el espesor de la capa. Polimerización. Condensación.

Evaporización para formar el Gel. Secado lento y tratamiento térmico para formar la capa vítrea.

Pueden realizarse, por esta técnica, películas de propiedades ópticas muy selectivas (Reflectantes, Antirreflectantes, de Color, Foto-Electrocrómicas, etc. etc.), películas de protección, conductoras, magnéticas, etc. etc.

\subsubsection{Productos compuestos. Vidrios y otros materiales}

El vidrio se asocia bien con otros materiales
Ces produits servent à limiter les pertes énergétiques des vitrages.

En résumé, avec cette nouvelle famille de nouveaux verres fonctionnels, le choix du verre support, la couche et la composition ou produit final de montage dans le bâtiment, on peut obtenir:

\section{- VERRES DE COULEUR ANTISOLAIRES.} Avec forte réflexion dans le visible et I'IR solaire (Faible Transmission Lumineuse et Facteur Solaire).

- VERRES NEUTRES ANTISOLAIRES. Faible réflexion et absorption dans le visible (Incolores) et haute réflexion dans l'IR solaire (bas FS).

- VERRES NEUTRES NON-EMISSIFS (Low-E). Ils permettent le passage de l'énergie solaire (lumière et chaleur) et réflètent le IR lointain. Ils facilitent les apports solaires et augmentent l'isolation.

Ainsi que les engagements et combinaisons entre eux, que permettent de résoudre la plupart des éxigences d'esthetique, de confort et les economies d'energie dans l'édification moderne.

\section{- Couches par sol-gel}

II s'agit d'une voie.peu utilisée encore à niveau industriel, mais avec un grand avenir pour les dépôts ou couches à propriétés sélectives. Conceptuellement et à niveau de laboratoire il a peu de limitations en ce qui concerne la nature et la purété des couches.

Il y a de différents processus, mais essentiellement il faut partir d'une solution -Solcontenant silice colloïdale en suspension et les autres composants de la couche en disolution. Immersion du verre à recouvrir et extraction à vitesse contrôlée pour ajuster l'épaisseur de la couche. Polymérisation. Condensation.

Vaporisation pour former le Gel. Séchage lent et traitement thermique pour former la couche vitreuse.

Avec cette technique, on peut réaliser des films à propriétés optiques trés sélectives

(Réflechissantes, Antiréflechissantes, de couleur, Photo-Electrochromiques, etc., etc.) films de protection, conductrices, magnétiques.

\subsubsection{Produits composites verres et d'autres materiaux}

L'association du verre avec d'autres matériaux 
(plásticos/metales/etc.) para dar lugar a productos compuestos con nuevas propiedades.

Las asociaciones más frecuentes en vidrio plano son:

- Vidrio/vidrio con diversos elementos de separación/unión/sellado.

- Vidrio/XXX/vidrio/... formando productos estratificados. Dando lugar a productos vidrieros muy conocidos y extendidos en el mercado:

\section{- Los acristalamientos múltiples} (principalmente, el doble acristalamiento del que se venden en Europa más de 50 millones de $\mathrm{m}^{2}$ por año), dedicados al aislamiento térmico.

- Los vidrios de seguridad por ensamblados de capas sucesivas vidrio/plastico,

y otros nuevos vidrios (aún en vías de desarrollo industrial) con propiedades muy especiales: vidrios con cristales líquidos; V. con películas holográficas; etc.

Habitualmente, se combinan en los acristalamientos los vidrios de color y las capas dentro de estos vidrios compuestos para dar lugar a productos muy completos que responden a las tres exigencias básicas de estética, confort y seguridad.

\section{- Acristalamientos múltiples}

Son productos vidrieros de uso muy extendido y suficientemente conocidos en sus aplicaciones en la construcción. El proceso de fabricación, sus componentes, su utilización, ... está perfectamente descrita en la numerosa bibliografía existente (vease MANUAL del VIDRIO del (ITAV). Solamente se recordará, a continuación, su función principal y se hará una referencia a los desarrollos actuales de estos productos.

Su función esencial es el aislamiento térmico, que se manifiesta por la resistencia del acristalamiento a transmitir el calor de una pared a la opuesta (V. tabla IX). El coef. de transmisión de calor $(K)$ depende de los espesores de los vidrios, de la cámara de separación de éstos y de los intercambios caloríficos en las distintas paredes.

Como resultado práctico de medidas, bajo condiciones pre-establecidas, se obtiene:

- V. monolítico: $\mathrm{K} 5,7 \mathrm{~W} / \mathrm{m}^{2}{ }^{\circ} \mathrm{C}$.

- D.A. (4/12/4): $\mathrm{K} 3,0 \mathrm{~W} / \mathrm{m}^{2}{ }^{\circ} \mathrm{C}$. (plastiques/métaux/etc.) donnent lieu à des nouveaux produits composites à proprietés nouvelles.

Les plus fréquentes associations en verre plat sont les suivantes:

- Verre/verre avec différents élements de séparation/union/étanchéité.

- Verre/XXX/verre/... en formant des produits stratifiés, donnant lieu à des produits verriers très connus et étendus sur le marché.

- Les vitrages multiples (principalement le Double Vitrage dont les ventes en Europe s'élévent à 50 millions de $\left.\mathrm{m}^{2} / \mathrm{an}\right)$, destinés à l'isolation Thermique.

\section{- Les Verres de Sécurité assamblage de couches succesives Verre/plastique,}

et d'autres nouveaux verres (en voie de développement industriel encore) avec des propriétés très spéciales. Verres à cristaux liquides, Verres à films, etc.

Habituellement dans les vitrages on combine les verres de Couleur et les couches à l'intérieur de ces Verres Composés donnant lieu à des produits trés complets qui réumissent les 3 exigences essentielles: Esthétique-Confort et Sécurité.

\section{- Vitrages multiples}

II s'agit de produits verriers d'usage très fréquent et assez connus dans le bâtiment. Le processus de fabrication, leur composants, son utilisation ... sont parfaitement décrits dans la nombreuse bibliographie existante (voir Manuel de Verre du CITAV). Ci-après on rappelera la fonction principale de ces vitrages ainsi que ses développements actuels.

L'isolation Thermique est sa fonction essentielle, dont la principale qualité est la résistance du vitrage pour trasmettre la chaleur d'une paroi à une autre opposée (Voir Table IX). Le coefficient de transmission de la chaleur $(K)$ dépend des épaisseurs des verres, de la chambre de séparation de ces verres et des échanges calorifiques dans les différentes parois.

Le résultat pratique de mesures, sous conditions pré-établies, donne:

- V. monolitique: $K=5,7 \mathrm{~W} / \mathrm{m}^{2}{ }^{\circ} \mathrm{C}$.

- D:V: $(4 / 12 / 4): K=3,0 \mathrm{~W} / \mathrm{m}^{2 \circ} \mathrm{C}$. 
TABLA IX TABLE IX

Materiales compuestos (Materiaux composés)

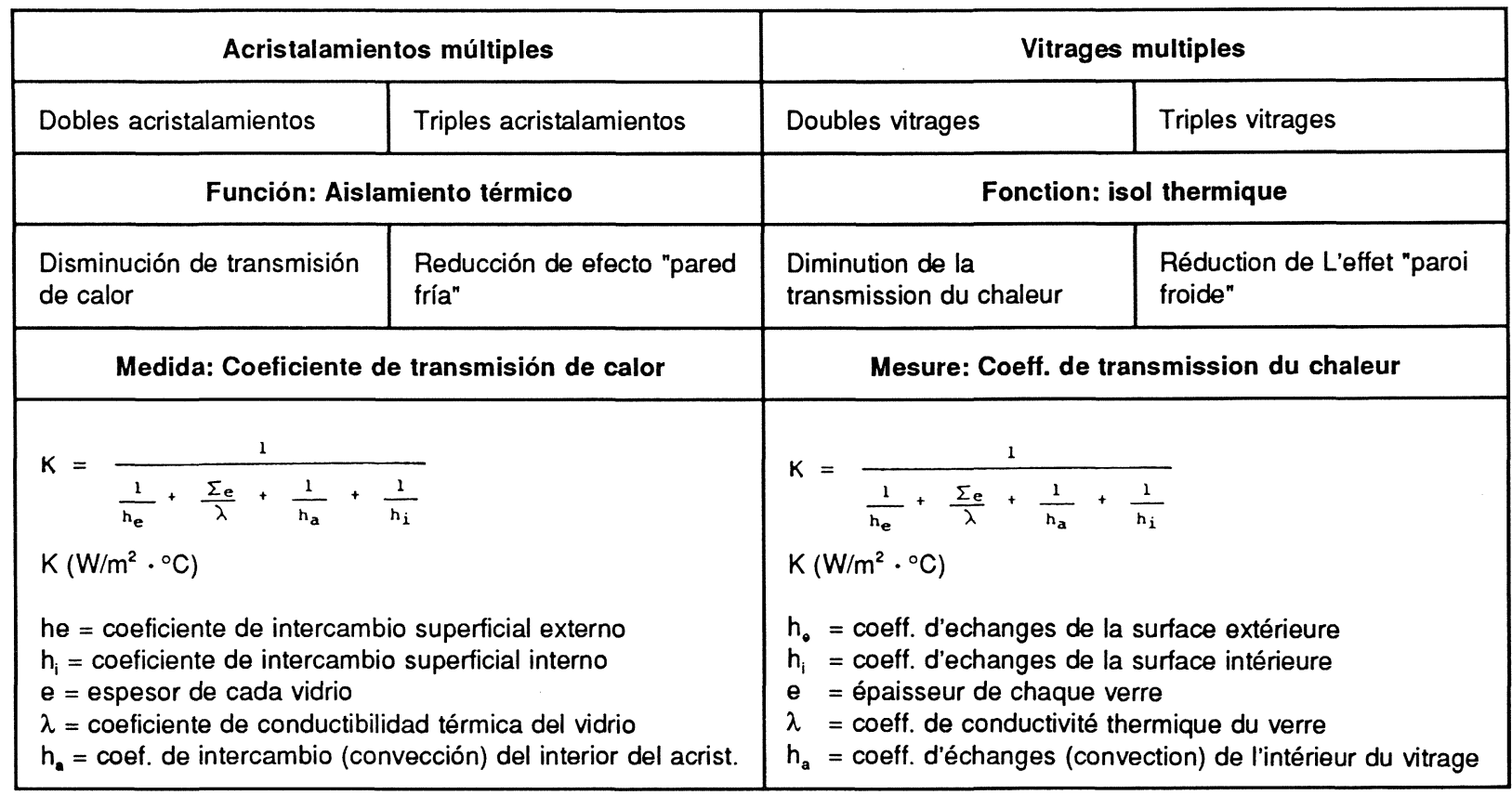

TABLA $X$ TABLE $X$

Aislamiento térmico de los acristalamientos

(Isolement thermique des vitrages)

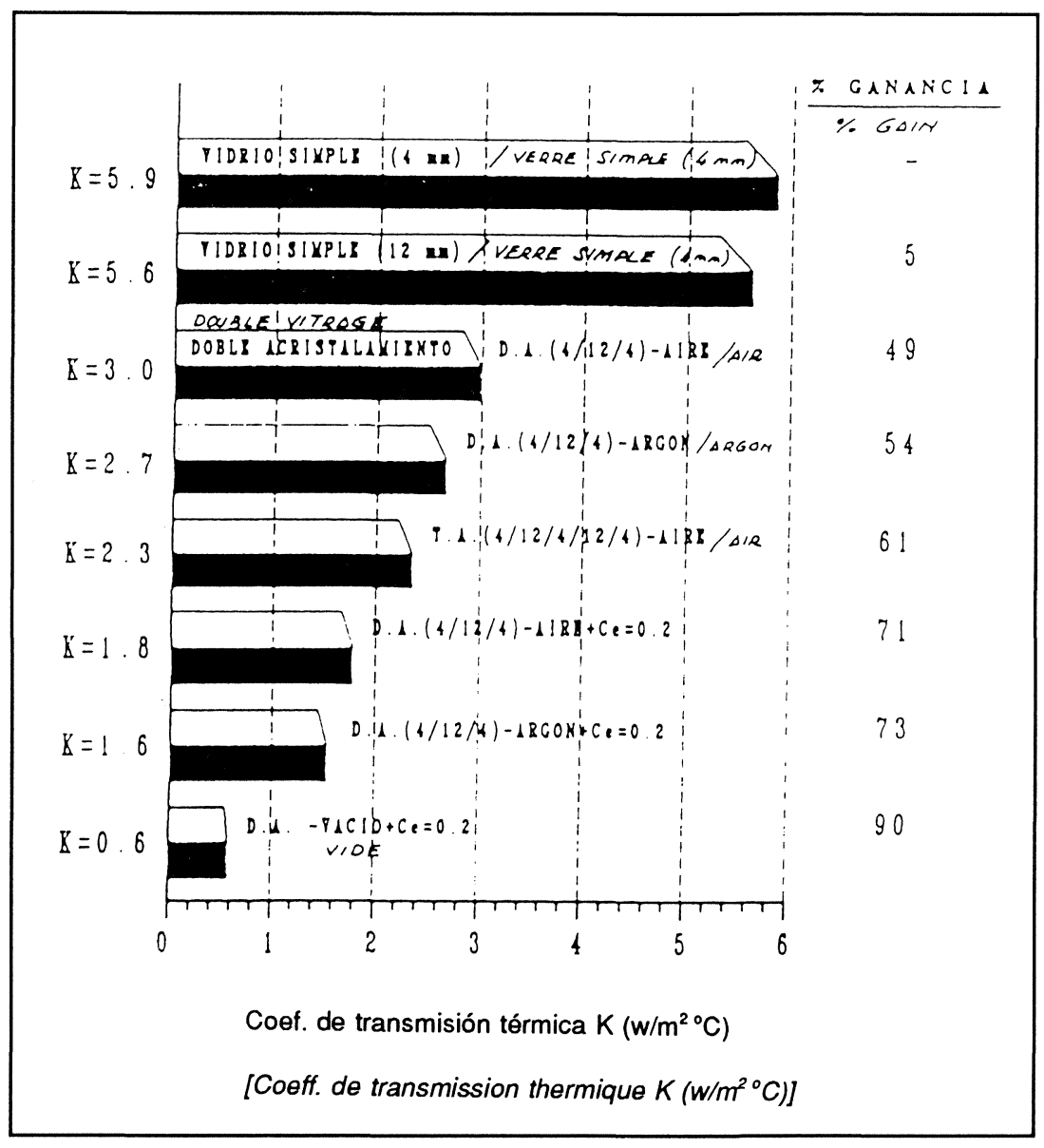


La evolución de estos productos está orientada a la reducción del coef. K (a la mejora del aislamiento térmico). Dos vías son preferentemente seguidas:

- Sustitución del aire de la cámara interior por otros gases con:

- Menor conducción térmica.

- Temperaturas de condensación más bajas.

- Espectros de absorción en el IR.

- Capas de baja emisividad que actúen como barrera a la radiación IR.

Con la combinación de ambas soluciones puede llegarse a acristalamientos con una ganancia en el aislamiento térmico superior al $70 \%$. En la tabla $X$ se expresan los valores del $\mathrm{K}$ para diversos tipos de acristalamientos.

$(\mathrm{Ce}=0,2$ significa que uno de los vidrios tiene en su cara interior una capa de emisividad $E=0,2$ ).

En estos productos se integran también otras funciones:

- Control solar.

Fabricándolos con vidrios/capas adecuados a este fin.

- Aislamiento acústico.

Eligiendo los espesores de las láminas de vidrio y de la cámara de aire se puede llegar a atenuaciones acústicas de los ruidos de circulación del órden de $35 \mathrm{~dB}(\AA)$.

- Seguridad.

Colocando en su exterior vidrios estratificados o laminares tipo "STADIP".

\section{- Vidrios estratificados}

Son vidrios compuestos, formando un solo bloque, de dos o más láminas de vidrio íntimimante unidas en toda su superficie por uno o varios films intercalarios. Los films se eligen teniendo en cuenta su plasticidad, resistencia, elasticidad, adherencia y alta calidad óptica después de un tratamiento térmico. En general son de Butyral de Polivinilo (PVB). Los vidrios e intercalarios una vez ensamblados se tratan en caliente bajo presión elevada para obtener un material compacto (un "COMPOSITE") de excelentes propiedades.

Son, principalmente, vidrios de seguridad en diversos grados:
L'évolution de ces produits est orientée vers la réduction du coefficient $K$ (amélioration de I'Isolation Thermique). II faut suivre deux voies:

- Remplacement de l'air de la chambre intérieure par d'autres gaz ayant:

- Plus faible conduction thermique.

- Températures de condensation plus basses.

- Absorption dans l'IR.

- Couches à faible émissivité jouant le rôle de barrière pour la radiation IR.

En combinant les deux solutions l'isolation Thermique des vitrages est supérieure au $70 \%$ Sur la Table $X$ sont exprimées les valeurs de $K$ par des différents types de vitrages.

( $C e=0,2$ signifie que l'un des verres a dans sa face intérieure une couche d'émissivité $E=0,2)$.

Ces produits possèdent aussi d'autres fonctions:

- Contrôle solaire.

La fabrication est réalisée avec verres/couches appropriés à ce but.

- Isolation acoustique.

On choisit les épaisseurs des plaques de verre et de la chambre d'air en obtenant ainsi la diminution acoustique des bruits de circulation de l'ordre de $35 d B(\mathbb{A})$.

- Sécurité.

On place à l'extérieur des verres stratifiés ou feuillétés type "STADIP".

\section{- Verres stratifiés}

Ce sont des verres composés, qui forment un seul bloc, avec deux ou plus de plaques de verre unies dans toute leur surface par un ou plusieurs films intercalaires. Les fibres sont choisies compte tenu de sa plasticité, résistance, élasticité, adhérence et haute qualité optique après un traitement thermique. Généralement ils sont de Butyral de Polyvinile (PVB). Après l'assemblage les verres et intercalaires sont chauffés sous pression élevée afin d'obtenir un matériel compact ("composite") d'excellentes propriétés.

Il s'agit principalement de verres de securite de différents degrés: 


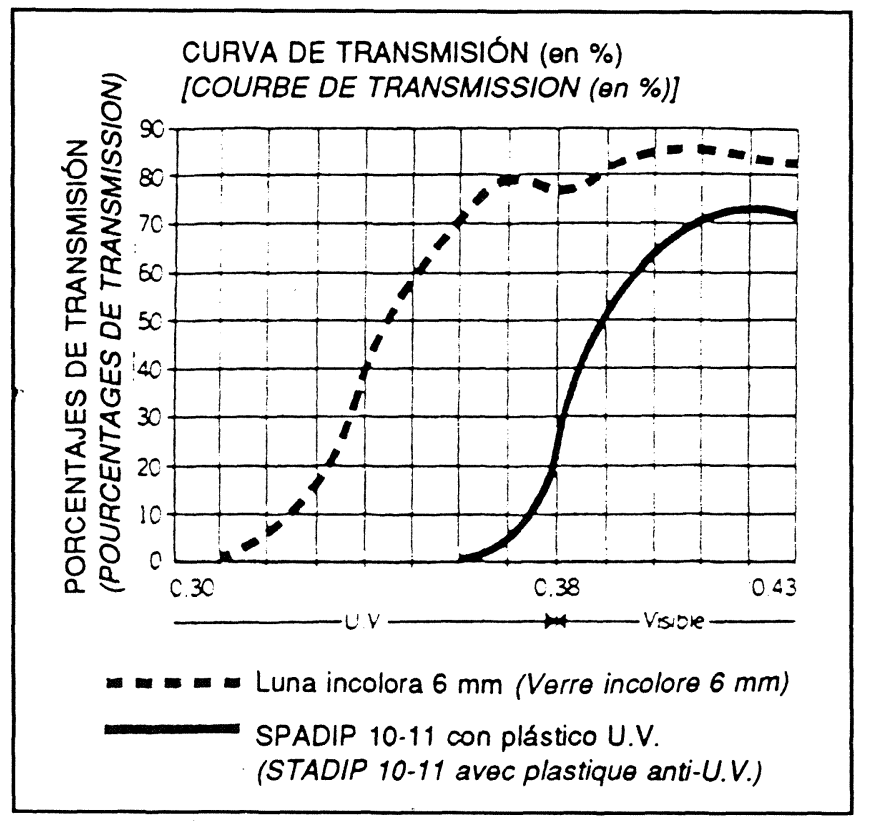

Fig. 4

- Reducen los riesgos de heridas cortantes y accidentes por penetración.

Resisten bien los impactos y cuando rompen, el vidrio queda adherido al plástico evitando riesgos de caídas o desprendimiento de trozos cortantes.

- Protegen de agresiones voluntarias, vandalismo, robo, disturbios...

- Puede formarse (en función del número de capas y espesor total) un blindaje contra la acción de armas de fuego.

(En las tablas XI y XII se dan las composiciones de algunos productos comerciales).

Además de la función principal de seguridad puede ampliarse su funcionalidad a campos como:

- Protección de la radiación solar (en combinación con capas reflectantes).

- Filtración de las radiaciones UV, desplazando el "cut-off" del UV solar hasta el dominio del visible (por el efecto unido del vidrio y de un PVB anti UV) (Fig. 4).

- Protección acústica. Basándose en la "ley de masas" la atenuación acústica de estos productos puede ser muy elevada.

Se resumen en la tabla XIII las características de atenuación acústica, a las distintas frecuencias, de diversos productos de vidrio mencionados hasta aquí.
- Ils réduisent les risques de blessures coupantes et accidents par pénétration.

Ils sont résistants aux impacts et quand ils brisent le verre reste fixé au plastique en évitant risques de chute ou éboulement de morceaux coupants.

- Ils protègent des agressions volontaires, vandalisme, vol...

- En fonction du nombre de couches et de l'épaisseur totale on peut former un blindage contre l'action des armes à feu.

(Dans les Tables XI et XII figurent les compositions de certains produits commerciaux).

En plus de la fonction principale de Sécurité ses fonctions peuvent être augmentées sur des domaines comme:

- Protection de la radiation solaire (en combinaison avec des couches réflechissantes).

- Filtration des radiations UV, en déplaçant le "cut-off" de l'UV solaire jusqu'a le domaine visible (par l'effet du verre uni au PVB anti UV) (Fig. 4).

- Protection acoustique. Sur le principe de la "loi de masses", l'atténuation acoustique de ces produits est très élevée.

Dans la Table XIII on a résumé les caractéristiques d'atténuation acoustique aux différentes fréquences, des divers produits de verre mentionnés jusqu'ici. 
TABLA XI TABLE XI

Gama de fabricación (Gamme de fabrication)

\begin{tabular}{|c|c|c|}
\hline Denominación (Dénomination) & $\begin{array}{c}\text { Composición y espesores de las } \\
\text { lunas } \\
\text { (Composition et épaisseurs } \\
\text { des glaces) } \\
\text { (mm) }\end{array}$ & $\begin{array}{c}\text { Dimensiones de fabricación } \\
\text { (Dimensions de fabrication) } \\
\text { (cm) }\end{array}$ \\
\hline Seguridad simple $A_{1}$ (Securité simple) & $3+3$ & $312 \times 201$ \\
\hline Seguridad fuerte $A_{2}$ (Securité forte) & $\begin{array}{c}4+4 \\
5+5\end{array}$ & $\begin{array}{c}420 \times 240 \\
420 \times 240 \\
750 \times 240\end{array}$ \\
\hline
\end{tabular}

TABLA XII TABLE XII

\begin{tabular}{|c|c|c|c|}
\hline $\begin{array}{l}\text { Nivel de energía } \\
\text { (Niveau d'energie }\end{array}$ & $\begin{array}{l}\text { Tipo de arma } \\
\text { (Type d'arme) }\end{array}$ & $\begin{array}{c}\text { Espesor STADIP } \\
\text { (Épaisseur STADIP) } \\
(\mathbf{m m})\end{array}$ & $\begin{array}{l}\text { N. }{ }^{\circ} \text { homologación } \\
\text { D.G.S.E. } \\
\text { (N. }{ }^{\circ} \text { d'homologation } \\
\text { D.G.S.E.) }\end{array}$ \\
\hline \multirow{2}{*}{$C_{1}$} & $\begin{array}{l}\text { Pistola STAR } 9 \mathrm{~mm} \\
\text { Parabellum }\end{array}$ & \multirow{2}{*}{$26 / 28$} & \multirow{2}{*}{00768} \\
\hline & Subfusil STARLING & & \\
\hline$C_{2}$ & $\begin{array}{l}\text { Revolver ASTRA } \\
357 \text { MAGNUM }\end{array}$ & $26 / 28$ & 00768 \\
\hline $\mathrm{C}_{3}$ & $\begin{array}{l}\text { Revolver ASTRA } \\
44 \text { MAGNUM }\end{array}$ & $43 / 45$ & 03230 \\
\hline \multirow{3}{*}{$\mathrm{C}_{4}$} & $\begin{array}{l}\text { Escopeta REMINGTON } \\
\text { Calibre } 12 \text { postas impactos } \\
\text { separados }\end{array}$ & $59 / 61$ & 03230 \\
\hline & $\begin{array}{l}\text { Escopeta REMINGTON } \\
\text { Calibre } 12 \text { postas impactos } \\
\text { superpuestos }\end{array}$ & $59 / 61$ & 03230 \\
\hline & $\begin{array}{l}\text { Escopeta REMINGTON } \\
\text { Calibre } 12 \text { bala de plomo } \\
\text { Brenneke }\end{array}$ & $59 / 61$ & 03230 \\
\hline $\mathrm{C}_{5}$ & Fusil CETME Cal. 7.62 & $59 / 61$ & 03230 \\
\hline
\end{tabular}

\section{- Otros vidrios compuestos}

Existen o están en vía de desarrollo industrial otras numerosas aplicaciones del vidrio combinado con otros materiales. Por su interés para la construcción, aunque se trata de productos especiales de uso limitado, se citan a continuación algunos de éstos:

\section{- Vidrios para-Ilamas}

Que impiden el paso de las llamas durante un cierto tiempo. El vidrio es incombustible pero

\section{- D’autres verres composés}

Il y a déjà ou sont en voie de développement industriel d'autres nombreuses applications du verre combiné avec d'autres matériaux. Ci après nous mentionnons certains de ces produits, utilisés principalement dans le bâtiment, et d'usage limité.

\section{- Verres pare-flammes}

Qui empéchent le pas des flammes pendant certain temps. Le verre est incombustible mais il 
TABLA XIII TABLE XIII

Características acústicas de los productos vítreos (Caractéristiques acoustiques des produits verriers)

\begin{tabular}{|c|c|c|c|c|c|c|c|c|c|c|c|c|c|}
\hline \multirow{3}{*}{ 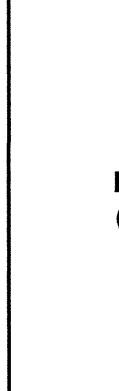 } & & & \multirow{3}{*}{$\begin{array}{c}\text { Es- } \\
\text { pesor } \\
\text { (Epai- } \\
\text { seur) } \\
\text { Total } \\
\text { mm }\end{array}$} & \multirow{3}{*}{$\begin{array}{l}\text { Peso } \\
\text { Poids } \\
\mathrm{kg} / \mathrm{m}^{2}\end{array}$} & \multicolumn{9}{|c|}{ Indice de atenuación acústica (Indice d'atténuation acoustique) } \\
\hline & \multirow{2}{*}{\multicolumn{2}{|c|}{$\begin{array}{l}\text { Productos } \\
\text { (Produits) }\end{array}$}} & & & \multicolumn{7}{|c|}{ Valores medios dB (Valeurs moyenes $\mathrm{dB}$ ) } & \multirow{2}{*}{$\begin{array}{c}\begin{array}{c}\text { Valo- } \\
\text { res } \\
\text { (Va- } \\
\text { leurs) }\end{array} \\
\begin{array}{c}\text { Ruido } \\
\text { Rosa }\end{array}\end{array}$} & \multirow{2}{*}{$\begin{array}{c}\text { Glo- } \\
\text { bales } \\
\text { (Glo- } \\
\text { baux) }\end{array}$} \\
\hline & & & & & $\begin{array}{c}125 \\
\mathrm{~Hz}\end{array}$ & $\begin{array}{c}250 \\
\mathrm{~Hz}\end{array}$ & $\begin{array}{l}500 \\
\mathrm{~Hz}\end{array}$ & $\begin{array}{c}1.000 \\
\mathrm{~Hz}\end{array}$ & $\begin{array}{c}2.000 \\
\mathrm{~Hz}\end{array}$ & $\begin{array}{c}4.000 \\
\mathrm{~Hz}\end{array}$ & $\begin{array}{c}125 / \\
4.000 \\
\mathrm{~Hz}\end{array}$ & & \\
\hline \multicolumn{14}{|c|}{ Acristalamientos simples (Vitrages simples) } \\
\hline $\begin{array}{l}\text { Lunas } \\
\text { (ve- } \\
\text { rres) } \\
\text { CRIS- } \\
\text { TAÑO- } \\
\text { LA }\end{array}$ & $\begin{array}{l}\text { reco- } \\
\text { cidas, } \\
\text { tem- } \\
\text { pladas, } \\
\text { inco- } \\
\text { loras, } \\
\text { color, } \\
\text { reflec- } \\
\text { tantes, }\end{array}$ & \begin{tabular}{|l} 
récuits, \\
trem- \\
pés, \\
inco- \\
lores, \\
couleur, \\
refle- \\
chi- \\
ssants,
\end{tabular} & $\begin{array}{r}3 \\
4 \\
5 \\
6 \\
8 \\
10 \\
15 \\
19\end{array}$ & $\begin{array}{l}7,5 \\
10 \\
12,5 \\
15 \\
20 \\
25 \\
37,5 \\
47,5\end{array}$ & $\begin{array}{l}18 \\
20 \\
20 \\
21 \\
24 \\
24,5 \\
28 \\
28,5\end{array}$ & $\begin{array}{l}22 \\
24,5 \\
26 \\
27 \\
28,5 \\
30,5 \\
32,5 \\
36\end{array}$ & $\begin{array}{l}24,5 \\
25,5 \\
28 \\
28,5 \\
31,5 \\
33 \\
34,5 \\
36\end{array}$ & $\begin{array}{l}30,5 \\
31,5 \\
33,5 \\
34 \\
34,5 \\
33 \\
32,5 \\
35,5\end{array}$ & $\begin{array}{l}33,5 \\
32 \\
30,5 \\
28,5 \\
29 \\
31 \\
36 \\
39,5\end{array}$ & $\begin{array}{l}25 \\
25,5 \\
28,5 \\
30,5 \\
34,5 \\
36,5 \\
41,5 \\
44,5\end{array}$ & $\begin{array}{l}25,5 \\
26,5 \\
27,5 \\
28 \\
30,5 \\
31,5 \\
34 \\
36,5\end{array}$ & $\begin{array}{l}26 \\
27 \\
29 \\
29 \\
31,5 \\
32,5 \\
35 \\
38\end{array}$ & $\begin{array}{l}26 \\
27,5 \\
29 \\
29 \\
31 \\
31,5 \\
33 \\
35,5\end{array}$ \\
\hline \multicolumn{14}{|c|}{ Acristalamientos aislantes (Vitrages isolants) } \\
\hline $\begin{array}{l}\text { CLI- } \\
\text { MALIT }\end{array}$ & \begin{tabular}{|l}
$4-4$ \\
$6-6$ \\
$10-5$
\end{tabular} & $\begin{array}{l}\text { cá- } \\
\text { mara } \\
\text { cham- } \\
\text { bre } \\
12 \\
12 \\
12\end{array}$ & $\begin{array}{l}20 \\
24 \\
27\end{array}$ & $\begin{array}{l}21 \\
31 \\
38,5\end{array}$ & $\begin{array}{l}23 \\
26 \\
23\end{array}$ & $\begin{array}{l}18 \\
23 \\
24\end{array}$ & $\begin{array}{l}24 \\
29 \\
28\end{array}$ & $\begin{array}{l}32 \\
34 \\
33\end{array}$ & $\begin{array}{l}34 \\
32 \\
38\end{array}$ & $\begin{array}{l}33 \\
40 \\
43\end{array}$ & $\begin{array}{l}27 \\
30 \\
32\end{array}$ & $\begin{array}{l}31 \\
33 \\
35\end{array}$ & $\begin{array}{l}28 \\
30 \\
32\end{array}$ \\
\hline \multicolumn{14}{|c|}{ Acristalamientos laminares de seguridad (Vitrages feilletés de sécurité) } \\
\hline STADIP & $\begin{array}{l}3+3 \\
5+4 \\
6+4 \\
3+6+3 \\
6+6+6 \\
6+6+6+\end{array}$ & ústico) & $\begin{array}{r}6 \\
9 \\
10 \\
12 \\
18 \\
24\end{array}$ & $\begin{array}{l}15,4 \\
23,3 \\
25,4 \\
30,8 \\
45,8 \\
61,2\end{array}$ & $\begin{array}{l}22 \\
25,5 \\
25 \\
25,5 \\
27 \\
29,5\end{array}$ & $\begin{array}{l}127,5 \\
30 \\
29,5 \\
32,5 \\
35 \\
37\end{array}$ & $\begin{array}{l}30,5 \\
33 \\
32,5 \\
36,5 \\
35,5 \\
36\end{array}$ & $\begin{array}{l}34 \\
34,5 \\
34,5 \\
34 \\
36,5 \\
40,5\end{array}$ & $\begin{array}{l}32 \\
36 \\
36 \\
38,5 \\
43,5 \\
47\end{array}$ & $\begin{array}{l}37 \\
43,5 \\
46 \\
47 \\
51 \\
51,5\end{array}$ & $\begin{array}{l}30,5 \\
34 \\
34 \\
35,5 \\
38 \\
40,5\end{array}$ & $\begin{array}{l}32,5 \\
35,5 \\
35 \\
36,5 \\
39 \\
41,5\end{array}$ & $\begin{array}{l}31 \\
33,5 \\
32,5 \\
34,5 \\
36 \\
38\end{array}$ \\
\hline
\end{tabular}

Atención: Estos valores están referidos al vidrio. En ningún caso indican el aislamiento acústico del conjunto vidrio + carpintería.

puede producirse su rotura por choque térmico. Se utilizan vidrios armados con mallas metálicas, para mantener la cohesión y asegurar la estanquidad a las llamas durante un cierto tiempo.

\section{- Vidrios corta-fuegos}

Además de impedir el paso de las llamas, limitan la tansmisión del calor al otro lado de la pared (evitando el incendio de materiales inflamables próximos: muebles, cortinas, etc.).

Un producto, ejemplo de esta gama, consiste en un doble acristalamiento con vidrios templados $y$ el espacio entre ambos lleno de un gel acuoso, peut briser par le choc thermique. On utilise des verres armés avec mailles métalliques afin de maintenir la cohésion et assurer l'étanchéité aux flammes pendant certain temps.

\section{- Verres coupe feu}

En plus d'empêcher le pas des flammes ils limitent la trasmission de la chaleur de l'autre côté de la paroi (évitant ainsi l'incendie de matériels inflammables proches: meubles, rideaux, etc...).

Un exemple de cette gamme est le double vitrage avec verres trempés et le espace entre eux rempli d'un gel aqueux, parfaitement transparent et 
perfectamente transparente e incoloro en condiciones normales. En caso de incendio, el gel reacciona con el calor, se transforma en una capa aislante y se vuelve progresivamente opaco a la radiación.

- Productos tipo "CONTRAFLAM" pueden mantenerse durante 60 ó 90 minutos con un gradiente térmico entre ambas caras de casi $800^{\circ} \mathrm{C}$.

\section{- Vidrios - policarbonatos}

Los estratificados de vidrios y policarbonatos tienen una gran resistencia mecánica y a los impactos de alta energía. Se utilizan normalmente en blindajes.

\subsubsection{Vidrios con propiedades variables}

Las investigaciones más recientes en el campo del vidrio plano se dirigen a la obtención de acristalamientos con posibilidades, técnicas y de coste, de ser industrializados, con propiedades que pueden ser alteradas en el acristalamiento instalado, ya sea a voluntad (p. ej.

"acristalamientos electrocomandados"), ya sea como reacción a las condiciones exteriores (los llamados "acristalamientos inteligentes"). De unos y otros se citan algunos de los más representativos:

\section{- Vidrios termocrómicos}

Son vidrios con ciertas capas que cambian sus propiedades ópticas por la acción del calor. Tienen esta propiedad las capas de óxido de vanadio $\left(\mathrm{VO}_{2}\right)$ que sufre una transición semiconductor-metal a $68^{\circ} \mathrm{C}$ (dopando el $\mathrm{VO}_{2}$ puede llegarse a los $25^{\circ} \mathrm{C}$ ).

\section{- Vidrios fotocrómicos}

Los vidrios que contienen agentes fotocrómicos cambian su transmisión luminosa (se produce el oscurecimiento) por el efecto de la irradiación. Este efecto es reversible volviendo a su estado anterior cuando desaparece el estímulo.

En general, es un efecto de masa en vidrios que contienen tierras raras, haluros de plata, halogenuros de cobre y cadmio, etc.

Son muy empleados en óptica. Su extensión a la construcción ha estado limitada, hasta ahora, por el elevado precio de sus componentes.

\section{- Vidrios electrocrómicos}

A diferencia de los anteriores, en este tipo de vidrios su propiedades ópticas son variadas a voluntad por el efecto de un potencial eléctrico. incolore en conditions normales. S'il y a un incendie le gel réagit avec la chaleur en formant une couche isolante et il se rend progressivement opaque à la radiation.

\section{- Produits type "CONTRAFLAM", maintient pendant 60/90 minutes un gradient thermique entre les 2 faces de presque $800^{\circ} \mathrm{C}$.}

\section{- Verres policarbonates}

Les stratifiés de Verres et Policarbonates ont une grande résistance mécanique et aux impacts d'haute énergie. Ils sont utilisés normalement pour les blindages.

\subsubsection{Verres avec propriétés variables}

Actuellement la recherche dans le domaine du verre plat a pour but l'obtention de vitrages avec des possibilités techniques et de coûts, avec des propriétés susceptibles d'être altérées sur le vitrage installé, bien volontairement (ex. "Vitrages Electrocommandés") bien en réagisant aux conditions extérieures (verres dénommés "Vitrages Intélligents"). Nous citons les plus répresentatifs:

\section{- Verres termochromiques}

II s'agit de verres avec certaines couches qui changent ses propriétés optiques par l'action de la chaleur. Les couches d'oxyde de Vanadium $\left(\mathrm{VO}_{2}\right)$ possèdent cette propriété qui souffre une transition semiconducteur-métal à $68^{\circ} \mathrm{C}$ (en dopant le $\mathrm{VO}_{2}$ on peut atteindre les $25^{\circ} \mathrm{C}$ ).

\section{- Verres photochromiques}

Les verres contenant des agents photochromiques changent leur transmission lumineuse (obscurcissement)par l'effet de l'irradiation. Cet effet est réversible, revenant à l'état antérieur lorsque la stimulation a disparu.

En général, il s'agit d'un effet de masse dans les verres contenant de terres rares, halures d'argent, halogénures de cuivre et cadmium, etc.

Ils sont très employés dans le domaine de l'optique. Son emploi dans le bâtiment a été jusqu'ici très limité à cause du prix de ses composants.

\section{- Verres electrochromiques}

Dans ce type de verres les propriétés optiques peuvent être vatiées volontairement par l'effet d'un potentiel électrique. 


\section{ELECTROCROMISMO / ELECTROCHROMISME}

Capas activas que cambian su transmisión luminosa al someterlas a una diferencia de potencial eléctrico.

Couches actives qui changent la tranmission lumineure sous l'effet d'un potential électrique

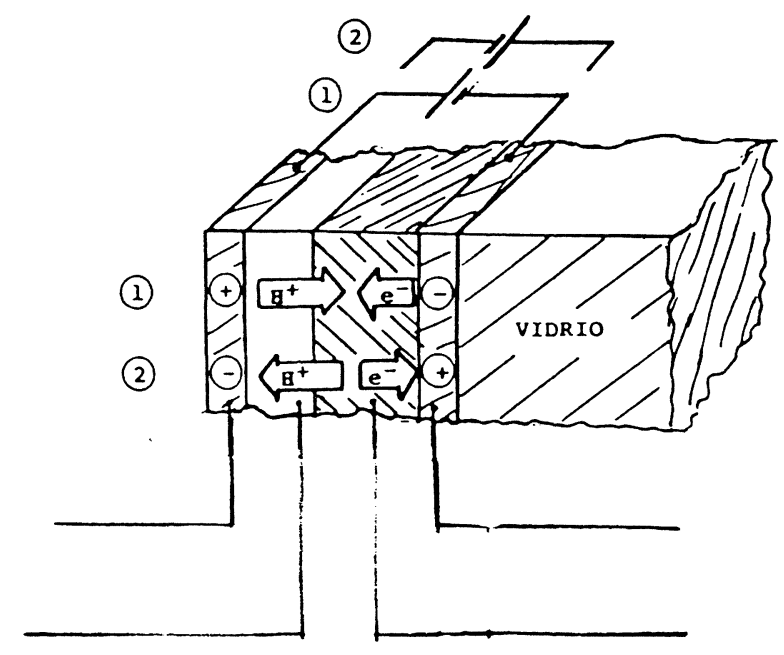

Paso de iones $\mathrm{H}^{+}$y e a la capa $\mathrm{WO}_{3}$ $\theta^{-}+W^{+5} \rightarrow W^{+5} \rightarrow$ oscurecimiento

(1)

Inversión del proceso

$W^{+5} \rightarrow W^{+6}+\theta \rightarrow$ transparencia

Passage d'ions $\mathrm{H}^{+}$y ëà la couche $\mathrm{WO}_{3}$ $e^{-}+W^{+5} \rightarrow W^{+5} \rightarrow$ obscurcissement

(2)

Inversion du processus

$W^{+5} \rightarrow W^{+6}+\theta^{-} \rightarrow$ transparence

Fig. 5

El mecanismo de estas capas (Fig. 5) es el cambio de valencia de ciertos óxidos semiconductores $\left(\mathrm{WO}_{3} ; \mathrm{V}_{2} \mathrm{O}_{5} ; \mathrm{M}_{0} \mathrm{O}_{3} ;\right.$ etc.), ocasionando bandas de transición en el visible.

Dicho cambio de valencia se produce inyectando simultáneamente electrones y cationes por ambos lados de la capa del compuesto electrocrómico.

El conjunto está formado por el apilado de varias capas sobre un vidrio $\left(\mathrm{S}_{n} \mathrm{O}_{2}\right.$-conductora/ $\mathrm{WO}_{3}$ electrocrómica/electrólito/ $\mathrm{S}_{n} \mathrm{O}_{2}$-conductora).

El tiempo de reacción es muy pequeño (segundos), cambiando la transmisión luminosa desde un $80 \%$ (max.) hasta un $5 \%$ (min.) de la luz incidente.

La reacción es reversible, mediante la aplicación de un potencial eléctrico de sentido contrario al inicial.
Le mécanisme d'action de ces couches (Fig. 5) est basé sur le changement d'état d'oxydation de certains oxydes semi conducteurs $\left(\mathrm{WO}_{3} ; \mathrm{V}_{2} \mathrm{O}_{5}\right.$; $\mathrm{MoO}_{3}$; etc.) qui forment des bandes de transition dans le visible.

Ce changement de valence a lieu en injectant de façon simultainée les électrons et des cations à travers les 2 faces de la couche du composé électrochromique.

L'ensemble est formé par l'empilage de différentes couches sur un verre $\left(\mathrm{SnO}_{2}\right.$ conductrice $\mathrm{WO}_{3}$ - électrochromique/ lélectrolyte $/ \mathrm{SnO}_{2}$ - conductrice).

Le temps de réaction est très petit (secondes) en changeant la transmission lumineuse de $80 \%$ (max.) jusqu'a $5 \%$ (min.) de la lumiére incidente.

La réaction est reversible, au moyen de l'application d'un potentiel électrique en sens contraire à l'initial. 


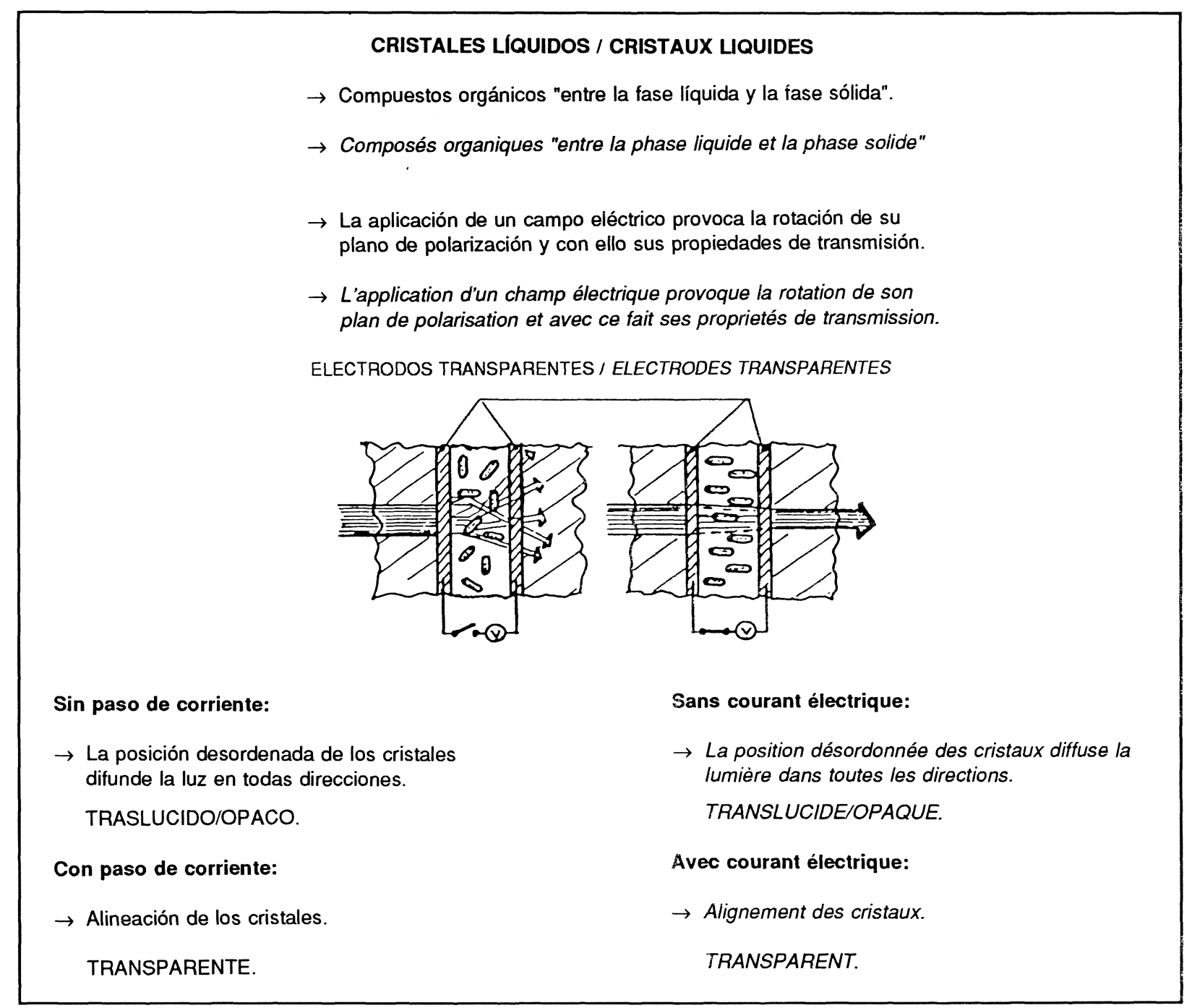

Fig. 6

Están ya desarrollados diferentes tipos, aunque sólo en dimensiones reducidas. Múltiples investigaciones en curso permiten asegurar que pronto serán productos utilizados en acristalamientos en la construcción.

\section{- Vidrios con cristales líquidos}

Los cristales líquidos son estados intermediarios entre la fase líquida y la fase sólida que presentan ciertos compuestos orgánicos (Fig. 6). Tienen, como variaciones, varias arquitecturas moleculares. En la fase "Nemática" poseen un orden orientacional. En la "Colestérica" una torsión. Estos dos estados presentan una transmisión luminosa diferente.

La aplicación de un campo eléctrico, bajo cierta frecuencia $\theta$ intensidad, puede hacer girar dichas moléculas y cambiar el espectro de transmisión (color) o solamente la difusión de la luz (la transparencia o la opacidad de los cristales).
On a déjà développé de différents types, mais en dimensions réduites. D'après de multiples recherches en cours on peut assurer que dans un court délai ces produits pourront être utilisés pour les vitrages dans le bâtiment.

\section{- Verres a cristaux liquides}

Les cristaux liquides sont des états intermédiaires entre la phase liquide et la phase solide que présentent certains composés organiques (Fig. 6). Il y a des variétés, telles que les architectures moléculaires. Dans la phase "Nématique" ils possèdent un ordre d'orientation. Dans la "Cholestérique" une torsion. Ces deux états présentent une transmission lumineuse différente.

L'application d'un champ électrique, sous certaine fréquence et intensité, peut faire tourner ces molécules et changer le spectre de transmission (couleur) ou seulement la diffusion de la lumière (transparence ou opacité des cristaux). 
- Láminas o películas fotográficas.

- Gelatina fotosensible sobre el vidrio.
- Plaques ou films photographiques.

- Gélatine photosensible sur le verre.

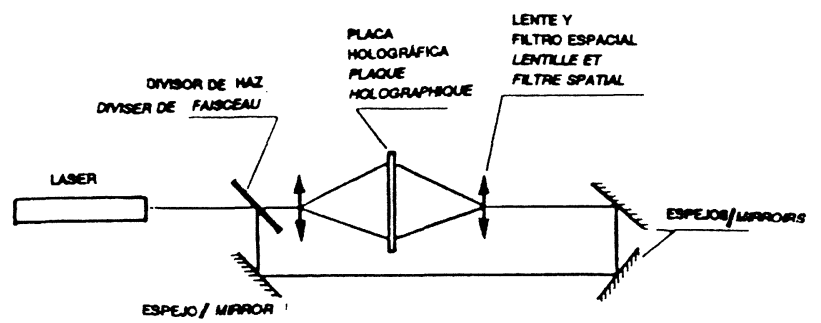

- Superposición sobre el HOLOGRAMA de dos ondas planas.

- Interferencias constructivas y destructivas en planos separados $\lambda / 2$ (Planos iluminados y planos oscuros que después del revelado dan lugar a Capas de índices de refracción altos y bajos).

\section{Resultados:}

- Capas que reflejan determinadas $\lambda_{D}$.

- Filtros de banda ancha (reflexión del IR y transmisión del visible sin dispersión cromática).
- Superposition sur L'HOLOGRAMME de deux ondes plates.

- Interférences constructives et destructives en plans separés $\lambda / 2$ (Plans éclairés et plans ombres qu'après le développement font apparaître couches d'indices de réfraction grands et petits).

Resultats:

- Couches qui réflechissent á $\lambda_{D}$ données.

- Filtres à large bande (réflexion dans L'I.R. et transmission dans le visible sans dispersion chromatique).

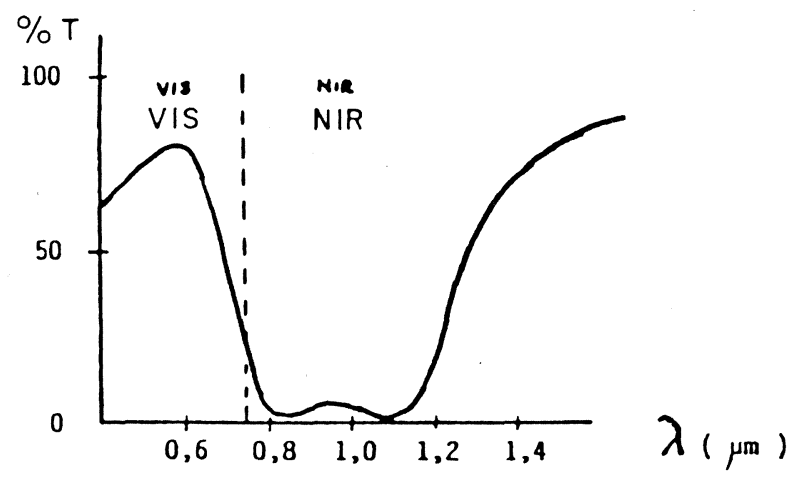

Fig. 7

Una aplicación, ya en el mercado, es el "PRIVALITE". Los cristales líquidos están contenidos en un film con sus superficies recubiertas de capas conductoras transparentes. Este film se sitúa dentro de un vidrio estratificado (dos placas) ensamblado con PVB.

Cuando se establece un campo eléctrico entre las dos superficies conductoras, los cristales se ordenan y el film, anteriormente translúcido (opalino), se vuelve transparente. Este cambio es totalmente reversible.
II y a déjà sur le marché une application le "PRIVA-LITE". Les cristaux liquides sont contenus dans un film avec ses surfaces couvertes de couches conductrices transparentes. Ce film est situé à l'intérieur d'un verre stratifié (2 plaques) assemblé avec PVB.

Lorsqu'un champ électrique est établi entre les 2 surfaces conductrices, les cristaux sont rangés et le film, antérieurement trans/ucide devient transparent. Ce changement est totalement reversible. 


\section{- Vidrios con películas holográficas}

Son vidrios estratificados que, además del intercalario de unión (PVB), llevan en su interior un film fotográfico sobre el que se han impresionado ondas coherentes, producidas por una radiación monocromática láser, provenientes de diferentes direcciones (Fig. 7).

Pueden producirse así, sobre la película, interferencias constructivas o destructivas entre las 2 ondas, en función del desfase entre ellas, debido a la diferencia de caminos recorridos. Si el objeto reproducido es una superficie plana y el soporte es transparente se produce un holograma con superposición de dos ondas planas.

Esta estructura de capas interferenciales puede reflejar determinadas longitudes de onda y permitir el paso de otras en función del ángulo de incidencia.

Aunque son productos cuya aplicación industrial está aún en fase de investigación, presentan un gran interés para la construcción. Una de sus aplicaciones puede ser la obtención de capas filtrantes selectivas (curva de la Fig. 7) que reflejen el IR y transmitan el visible sin dispersión cromática. También podría dar lugar a acristalamientos de colores cambiantes en función de la incidencia de la luz.

Actualmente, comienzan a difundirse en el campo de la información y la publicidad (imágenes en tres dimensiones).

\subsubsection{Vidrios laminados o impresos}

Forman parte de la gama más antigua dentro de la familia del vidrio plano actual. Son sobradamente conocidos en la construcción por su extendida utilización durante muchos años (cierres de naves, mamparas interiores de separación, luninarias; puertas; etc. etc.)

Se producen por colada y laminación de un vidrio fundido entre dos rodillos metálicos, de los que uno esta gravado, imprimiendo un dibujo en relieve sobre una de las caras del vidrio. El producto final es una hoja de vidrio plano que produce una dispersión de la luz (producto translúcido) y con una transmisión luminosa del 50 al $90 \%$ según el color. Sus restantes propiedades físicas son similares al resto de productos de vidrio plano.

Dos variantes interesantes en la construcción son:

- VIDRIOS IMPRESOS TEMPLADOS. Con temple físico, para aumentar su resistencia mecánica y al choque térmico.

\section{- Verres à films holographiques}

Il s'agit de verres stratifiés qu'en plus de l'intercalaire d'union (PVB), portent à l'intérieur un film photograhique sur lequel on a impressionné des ondes cohérentes, originées par une radiation monochromatique laser, provenant de différentes directions.

On peut trouver alors, sur ie film, des interférences constructives ou destructives entre les 2 ondes, en fonction du déphasage entre elles, d'après la différence des chemins parcourus. Si l'objet réproduit est une surface plate et le support est transparent se forme un hologramme avec superposition de deux ondes plates.

Cette structure de couches interferentielles peut réfleter des longueurs d'onde déterminées en permettant le pas d'autres ondes en fonction de l'angle d'incidence.

II s'agit de produits dont l'application industrielle est encore en phase de recherche, mais ils présentent un grand intérêt pour la construction. Ils peuvent être appliqués pour l'obtention de couches filtrantes sélectives (courbe de la Fig. 7) qui réflechissent l'IR et transmettent le visible sans dispersion chromatique. Ils pourraient être utilisés aussi dans les vitrages à couleurs variables en fonction de l'incidence de la lumière.

Actuellement, la diffusion commence dans le domaine de l'information et la publicité (images en tres dimensions).

\subsubsection{Verres feuilletés ou imprimes}

Ils font partie de la gamme plus ancienne dans la famille du verre plat actuel. Ils sont très connus dans le bâtiment par son utilisation habituelle pendant beaucoup d'années (fermetures de bâtiments industriels, paravents intérieurs de séparation, luminaires, portes, etc...).

Les verres sont fabriqués par coulée et feuilletage d'un verre fondu entre deux rouleaux métalliques, l'un de ces rouleaux est gravé, en imprimant un dessin en rélief sur une des faces du verre. Le résultat final est une feuille de verre plat qui produit une dispersion de la lumière (produit translucide) et avec une transmission lumineuse du 50 au $90 \%$ selon la couleur. Les autres propriétés physiques sont similaires à celles du reste des produits de verre plat.

II y a deux types d'applications dans le bâtiment:

- VERRES IMPRIMES TREMPES. Avec trempe physique, afin d'augmenter sa résistance mécanique et le choc thermique. 
- VIDRIOS IMPRESOS ARMADOS. Llevan incorporada en su masa una malla metálica soldada, de retícula cuadrada, introducida durante la laminación. Además de impedir la penetración y reducir el peligro de rotura y desprendimiento de trozos, son utilizados también como productos para-llamas.

Estos vidrios también pueden ensamblarse entre sí o con otros vidrios planos de caras lisas formando dobles acristalamientos o estratificados. Además de las utilizaciones mencionadas, encuentran su maximo empleo por su aspecto decorativo y la difusión de la luz evitando la visión directa a través de ellos.

\section{VIDRIOS ESTRUCTURALES}

A veces se utilizan los productos de vidrio plano (vidrios templados, v. estratificados, acristalam. aislantes, etc.) como elementos estructurales en la construcción. Las uniones vidrio-metal (por medio de adhesivos, siliconas, etc.) han extendido la utilización de conjuntos pre-montados que tienen funciones de acristalamientos estructurales.

Además de las aplicaciones de compuestos de vidrio plano, existen otros productos de vidrio, expresamente diseñados para ser elementos resistentes en la construcción. Entre ellos, los de uso más conocidos y frecuente son:

\section{- Perfiles en U (U-Glas)}

Son perfiles de vidrio, obtenidos por laminación y plegado, con sección en forma de U. Los bordes están pulidos al fuego. La forma de $U$ y la ausencia de micro-fisuras en los bordes los confiere una buena resistencia a la flexión. Pueden estar "armados", es decir, con una malla metálica en el interior de la masa de vidrio, para aumentar su seguridad.

Con este tipo de perfiles pueden construirse grandes paramentos, cubiertas, lucernarios, eic. sin necesidad de una estructura de perfiles metálicos. Diversas combinaciones posibles dan lugar a cerramientos simples o dotados de cámara aislante (tanto térmica como acústica).

\section{- Moldeados de vidrio}

Son piezas de vidrio translúcido, obtenidas por prensado del vidrio fundido dentro de moldes metálicos de los que toman su forma.

Las piezas así obtenidas (moldeados sencillos) pueden ser utilizados directamente en parámetros o en pisos (baldosas) unidas entre sí con una estructura de hormigón armado u otro material rigidizador.
- VERRES IMPRIMES ARMES. A l'intérieur, dans la masse ils portent une maille métallique soudée, à réticule carrée, introduite pendant le laminage. Ils empêchent la pénétration ế réduisent le risque de brisure et la production des morceaux, en plus ils sont utilisés comme produits pare-flammes.

Ces verres peuvent être assemblés en euxmêmes ou avec d'autres verres plats à faces plates en iormant de doubles vitrages ou stratifiés. II faut ajouter aux utilisations déjà mentionnées son emploi décoratif, et la diffusion de la lumière en évitant la vision directe à travers d'eux.

\section{VERRES STRUCTURELS}

Souvent on utilise les produits de verre plat (verres trempés, verres stratifiés, vitrages isolants, etc.) comme éléments structurels dans la construction. Les unions verre-métal (au moyen d'adhésifs, silicones, etc.) ont développé l'utilisation de prémontages comme vitrages structurels.

En plus des applications de composés de verre plat, il y a d'autres produits, proprement dessinés pour servir d'éléments résistants dans la construction. Parmi ceux-ci, les plus connus sont les suivants:

\section{- Profils u (U-Glass)}

Il s'agit de profils en verre, réalisés par laminage et plié, avec section en forme d'U. Les bords sont polis au feu. La forme d'U et l'absence de microfissures dans les bords leurs rendent très résistants à la flexion. Ils peuvent être armés, c'est à dire, avec une maille métallique à l'intérieur de la masse de verre, pour augmenter la sécurité.

Avec ce type de profils on peut construire de grands parements, revêtements, lucernaires, etc. n'ayant pas besoin de structure à profils métalliques. En réalisant de différentes combinaisons on obtient des fermetures simples ou avec une chambre isolante (thermique ou acoustique).

\section{- Moulages de verre}

Ce sont des pièces en verre translucide, obtenues par le pressage du verre fondu dans un moule métallique dont ils prennent leur forme.

Les pièces ainsi obtenues (moulages simples) s'utilisent directement dans les parements ou sols (dalles) unies entre elles avec una structure de béton armé ou un autre matériel rigide. 
Unidas cada dos piezas mediante soldadura "vidrio a vidrio" se consiguen los moideados dobles con formas de paralelepípedos cuadrados - rectangulares y una cámara interior de aire seco y presión reducida (por haber sido soldados en caliente $600^{\circ} \mathrm{C}$ ). Estas piezas constituyen auténticos "ladrillos o bioques" de vidrio, con una aceptable transmisión luminosa ( $\approx 80 \%$ en V. incoloro) y buen comportamiento como aislamiento férmico $(K \propto 3)$ y acústico [atenuación de $35 \mathrm{~dB}(\AA)$ ]. Se fabrican en vidrio incoloro $y$ en varios colores.

Se pueden utilizar en fachadas, tabiques interiores y exteriores y todo tipo de paramentos. Se unen entre sí mediante morteros armados $u$ otros sistemas diseñados especialmente para este uso.

Además de la buena resistencia mecánica de este tipo de construcción, los muros translúcidos, con la armadura de mortero y varilla metálica, @stán también clasificados como "para-llamas 2 horas".

\section{FIBRAS DE VIDRIO}

La particularidad del vidrio en estado plástico de comportarse como un buen líquido newtoniano, es decir, la posibilidad de un estirado sin rotura bajo el efecto de una tracción, justifica el conocimiento y uso, desde época muy antigua, de los hilos y fibras de este material.

Aunque ya en el siglo XVIII se intenta la utilización de la fibra de vidrio en usos textiles, es con la aparición de los nuevos procedimientos de fibrado (estirado-soplado, centrifugación, estirado por hileras, eic.) cuando comienza a extenderse la aplicación de estos productos en numerosos usos industriales.

En su aplicación a la construcción se dividen las fibras en dos grandes familias:

\section{- LANAS de AISLAMIENTO.}

\section{- FIBRAS de REFUERZO.}

con diferencias importantes tanto en el proceso de fabricación como en las características físicas (diámetro y longitud) y químicas (composición) y, consecuentemente, con utilizaciones muy diferenciadas.

\section{- Lanas de aislamiento}

Se desarrolla su uso con la necesidad de sustitución de otros aislantes tradicionales (corcho, amianto, etc.) a partir de la 1. ${ }^{a}$ guerra europa (1914-1918).
Par lunion de deux pièces au moven de soudure ¿ chaud, "verre à verre" on obtient les Moulages Doubles avec des formes de parallélépipèdes carrés ou rectangulaires ayant à fintérieur une chambre d'air sec et pression réculuite (du fait qu'ils ont été soudés en chaud $\approx 600^{\circ} \mathrm{C}$ ). Ces pièces réprésentent de véritables "briques ou blocs" de verre, avec une acceptable transmission lumineuse $(\propto 80 \%$ en V.Clair) et avec bon comportement comme isolants thermiques $(K \propto 3)$ et acoustiques [atténuation de $35 d B(A)]$. ils sont fabriqués en verre clair et différentes couleurs.

Ils s'appliquent sur façades, cloisons intérieurs et extérieurs et sur n'importe quel type de parements. L'union entre eux se réalise au moyen de mortiers armés ou d'autres systèmes spécialement dessinés pour cet usage.

En plus de la bonne résistance mécanique de ce type de construction, les parois translucides, avec armature de mortier et baguette métallique, peuvent être aussi classifiés comme "pareflammes 2 heures".

\section{FIBRES DE VERRE}

La particularité du verre en état plastique de se comporter comme un bon liquide "newtonien", c'est à dire, la possibilité de l'étirage sans brisure sous l'effet d'une contrainte d'extension, justifie la connaissance et l'usage des fils et fibres de ce matériel, depuis l'époque très ancienne.

Déjà au XVIIPme siècle on tente d'employer la fibre de verre pour des usages textiles, mais jusqu'à l'apparition des nouveaux procédés de fibrage (étirage-soufflé, centrifugation, étirage par filières, etc.) on ne commence pas à connaître l'application de ces produits sur des nombreux usages industriels.

D'après son application on peut diviser les fibres en deux grandes familles:

\section{- LAINES D'ISOLATION.}

\section{- FIBRES DE RENFORCEMENT.}

avec d'importantes différences aussi bien dans le processus de fabrication que dans les caractéristiques physiques (diamètre et longueur) et chimiques (composition) et, en conséquence, ayant des utilisations très différentes.

\section{- Laines d'isolation}

Elles servent à remplacer d'autres isolants traditionnels (liège, amiante, etc.) à partir de la $1^{\text {ere }}$ guerre européenne (1914-18). 
Uno de los procedimientos de fabricación más extendido es el de centrifugación del vidrio fundido en un plato giratorio con numerosas perforaciones, seguido del estirado de los hilos formados por la acción mecánica y térmica de un quemador circular con alta velocidad de la llama (procedimiento TEL). La composición química es característica de un vidrio de sílice, pero conteniendo ciertos componentes estabilizantes de la estructura vítrea que añaden al producto particulares mejoras en su resistencia al calor, su conductividad térmica y su comportamiento al envejecimiento.

Después del estirado final de las fibras se añade por pulverización una resina aglomerante que las impregna antes de ser depositadas sobre un tapíz metálico por aspiración. Entran así en una estufa de polimerización donde a la vez se prensan con otro tapíz para obtener los paneles del espesor, densidad y rigidez deseados.

Las características principales de estos productos son:

- Baja conductividad térmica (entre 0,028 y 0,04 $\left.\mathrm{kcal} / \mathrm{h} \cdot \mathrm{m}^{\circ} \mathrm{C}\right)$.

- Productos ligeros (densidades entre 10 y 110 $\mathrm{kg} / \mathrm{m}^{3}$ ).

- Eficacia de la absorción acústica y de las vibraciones.

- Incombustibles, inatacables por los agentes ambientales, neutros $(\mathrm{pH} \propto 7)$, inocuos y de larga duración.

- Facilidad de manipulación y adaptación a las superficies.

Su utilización más extendida tanto en la construcción como en el sector industrial es como producto de aislamiento térmico (paredes, pisos, techos, tuberías, etc. etc.) y de aislamiento acústico. Existe una amplia gama de productos (más de 400) que facilita la elección del idóneo para cada utilización.

\section{- Fibras de refuerzo}

El vidrio bajo la forma de fibras finas tiene una importante aplicación en la construcción y en la industria en general como refuerzo de otros materiales (plásticos, cemento, etc.).

El proceso de obtención más extendido es la fusión del vidrio y su estirado a elevada temperatura. Esta operación se hace mediante colada del vidrio por gravedad, en "hileras" de platino con numerosos y pequeños taladros, y un estirado mecánico a elevada velocidad (> 100 $\mathrm{m} / \mathrm{seg}$.), dando lugar a filamentos entre 5 y $24 \mu \mathrm{m}$
Le procédé de fabrication le plus connu est par centrifugation du verre fondu sur un plateau avec de nombreuses perforations, suivi de l'étirage des fils formés par l'action mécanique et thermique d'un brûleur circulaire à haute vitesse de la flamme (procédé TEL). La composition chimique est caractéristique d'un verre de silice, mais en contenant certains composants stabilisants de la structure verrière ajoutant au produit des améliorations particulières face à la résistance à la chaleur, à la conductivité thermique et son comportement face an vieillissement.

Aprés l'etirage final des fibres on ajoute une résine agglomérante par pulvérisation les impregnant avant d'être deposées sur un tapis métallique par aspiration. Elles entrent ainsi dans une étape de polymerisation où elles sont pressées avec un autre tapis pour obtenir des panneaux d'épaisseur, densité et rigidité souhaités.

Les principales caractéristiques de ces produits sont:

- Basse conductivite thermique (entre 0,028 et $\left.0,04 \mathrm{Kcal} / \mathrm{h} . \mathrm{m}^{\circ} \mathrm{C}\right)$.

- Produits Légers (densités entre 10 et 110 $\mathrm{kg} / \mathrm{m}^{3}$ ).

- Efficacité de l'absorption acoustique et des vibrations.

- Incombustibles, inattaquables par les agents de l'environnement, neutres $(\mathrm{pH} \approx 7)$, non nuisibles et à longue durée.

- Manipulation facile et adaptation aux surfaces.

Ces produits sont utilisés surtout dans le bâtiment et dans le secteur industriel comme produits d'isolation thermique (parois, sols, toits, tuyautérie, etc...) et d'isolation acoustique. II y a une ample gamme de produits (plus de 400) ce qui rend plus facile le choix du plus convenable pour chaque utilisation.

\section{- Fibres de renforcement}

Le verre sous la forme de fibres fines a une importante application dans le bâtiment et dans l'industrie en générale comme renforcement d'autres matériaux (plastiques, ciment, etc.).

Le processus d'obtention le plus diffusé est celui de la fusion du verre et son étirage à haute température. Cette opération est réalisée au moyen de coulée du verre par gravité, en "filières" de platine avec de nombreux trous, et un étirage mécanique à haute vitesse (> $100 \mathrm{~m} / \mathrm{seg}$.) donnant lieu à des filaments entre 5 et $24 \mu \mathrm{m}$ de 
de diámetro, según sea su aplicación. Dichos filamentos se revisten de una solución acuosa de compuestos orgánicos "ensimage" que une y lubrifica las fibras y las disponde para las aplicaciones o transformaciones posteriores.

Son productos muy especializados, diferenciándose ya desde la propia composición del vidrio. Entre los más representativos están los siguientes:

— Vidrio "E" (el más utilizado) con una matriz de boro-silicato.

— Vidrio "R" (de gran resistencia mecánica) está enriquecido en Sílice y Alúmina.

- Vidrio "D" (para aplicaciones eléctricas) con elevado contenido en Boro.

- Vidrio "AR" (muy resistente a los álcalis) con alto contenido de Zirconio.

Sus propiedades físicas varian con el vidrio y con el tipo de producto. En general, tienen una elevada resistencia a la tracción $\left(1.000 \mathrm{~kg} / \mathrm{mm}^{2}\right)$ y su módulo de elasticidad $\left(7.000 \mathrm{~kg} / \mathrm{mm}^{2}\right)$ es igual al del aluminio. Son incombustibles, imputrescibles, y tienen un buen comportamiento frente a la mayor parte de los agentes químicos.

En su extendida aplicación a la construcción pueden diferenciarse dos grandes familias de productos:

\section{- Plasticos reforzados con fibra de vidrio}

Son asociaciones (composites) de fibras de refuerzo (en general de tipo "E") con matrices orgánicas (principalmente, poliester). La fibra transmite al composite su resistencia mecánica.

Aunque su mayor utilización es sustituyendo a otros materiales en la construcción de barcos, coches, electrodométicos, materiales de decoración, etc., cada vez es más importante su implantación en la edificación: Paramentos, paneles de separación, paneles de aislamiento térmico y acústico, decoración, cubiertas de edificios, sanitarios, etc. etc. (En Europa, se consumen del órden de 500.000 taño de estas fibras de vidrio y su crecimiento anual es del $12 \%)$.

\section{- Cementos reforzados con fibra de vidrio}

Son COMPOSITES vidrio-cemento. Utilizan una fibra de vidrio, la "AR" (alcali-resistente) especialmente concebida para resistir bien la agresión de los componentes del cemento y el envejecimiento en condiciones severas de utilización. diamètre selon l'application. Ces filaments sont revêtus d'une solution aqueuse de composés organiques "ensimage" qui assemble et lubrifie les fibres pour les applications ou transformations postérieures.

II s'agit de produits très spécialisés. Les plus représentatifs sont les suivants:

- Verre "E" (le plus utilisé) avec une matrice de bore silicate.

- Verre "R" (à grande résistance mécanique) il est enrichi de Silice et Alumine.

- Verre "D" (pour des applications électriques) ayant un élevé contenu en Bore.

- Verre "AR" (très résistant aux alcalis) ayant un élevé contenu de Zirconium.

Les propriétés physiques variant avec le verre et avec le type de produit. En général, sa résistance à la traction est élevée $\left(1.000 \mathrm{Kg} / \mathrm{mm}^{2}\right)$ et son module d'élasticité $\left(7.000 \mathrm{Kg} / \mathrm{mm}^{2}\right)$ est le même que celui de l'aluminium. Ils sont incombustibles et son comportement face a la plupart des agents chimiques est bon.

D'après son application dans le bâtiment on peut mentionner deux grandes familles de produits:

\section{- Plastiques renforcés avec fibres de verre}

Ce sont des associations (composites) de fibres de renforcement (généralement du type " $E$ ") avec de matrices organiques (principalement Polyester). La fibre transmet au composite sa résistance mécanique.

Son utilisation plus étendue est pour remplacer d'autres matériaux dans la construction de bateaux, voitures, appareils, électroniques, matériaux de décoration, etc., mais actuellement son implantation dans le bâtiment, devient de plus en plus important: parements, panneaux de séparation, panneaux d'isolation thermique et acoustique, décoration, revêtements de bâtiments, sanitaires, etc... (La consommation annuelle en Europe de ces fibres de verre est de l'ordre de 500.000 T/an et sa croissance annuelle est de l'ordre de $12 \%$ ).

\section{- Ciments renforcés avec fibre de verre}

II s'agit de COMPOSITES verre-ciment. I/s utilisent une fibre de verre, "AR" (alcali-résistante) connue essentiellement pour bien résister l'agression des composants du ciment et le viellissement dans des conditions d'utilisation. 
Son productos modernos y por ello su aplicación no está aún demasiado extendida. Se espera un importante crecimiento de su empleo en aplicaciones como: Paneles en fachadas con revestimientos de otros materiales (piedra, hormigón, etc.), posibilitando una gran libertad de forma y superficies y el aspecto estético deseado. Pre-fabricados integrando diversas funciones (conducciones, desagües, aislamientos, etc.) Cubiertas de edificios. Tuberías, Alcantarillado. Muebles de jardín. etc. etc.

Próximamente, se iniciará la fabricación de estas fibras en España para abastecer aproximadamente un $60 \%$ del mercado mundial.
Ce sont des produits modernes et en conséquence son utlisation est encore peu étendue. On attend une importante croissance de ces produits sur des applications telles que: Panneaux sur façades avec revêtements d'autres matériaux (pierre, béton, etc), en rendant possible une grande liberté de formes et surfaces et l'obtention de l'aspect esthétique souhaité. Préfabriqués ayant de différentes fonctions (conductions, écoulements, isolation, etc). Couvertures de bâtiments. Tuyautéries. Egouts. Meubles de jardin, etc...

Prochainement, nous commencerons à fabriquer ces fibres en Espagne pour fournir environ $60 \%$ du marché mondial.

\section{BIBLIOGRAFIA}

- BEEK; MANFRED: Patente sobre APLICACION de la HOLOGRAFIA para PELICULAS de REFLEXION ( . $^{\circ}$ DE 3822814 A1). (en Alemán).

- BRAULT, C.: Les depots physiques en phase vapeur. Matériaux et Techniques, Jul. Ag. (1989).

- BUTTON, David A.: Glass for the year 2000. Glass Digest, Enero 15 (1990).

- CITAV: Manual del Vidrio (1989).

- CHEVALIER, J. L.: Des vitrages innovants pour le bâtiment. CSTB Magazine, n. 5 Jun. (1987).

- CHEVALIER, J. L.; Fremaux, J.: Les vitrages a Faible, emissivité. CSTB Magazine n. 4 Mayo (1987).

- FERNANDEZ NAVARRO, J. M.: El vidrio - CSIC (1985).

— FREMAUX, J.: Les vitrages à propriétés variables et commandables. Agence Française pour la maîtrise de l'énergie. Journées "ISOLATION'88".

- FREMAUX, J.; SAUVINET, J.: Dépôt en continu de couche à basse émissivité sur verre flotté par pyrolyse de poudre. Rivista della Staz. Sper. Vettro, 6 (1986).

- ISOVER: Manual del aislamiento (1984).

- MARI, E. M.: Los vidrios. Edit. Américalee (1982).

- MASSARELLI, L.: Control of optical and thermal properties of float glass by coatings. Rivista della Staz. Sper. Vettro, 6 (1986).

— MEURTIN, B.: L'architecte et les vitrages. Agence Française pour la maîtrise de l'énergie. Journées "ISOLATION'88".

- PERSSON, H. RUNE: Glass technology. Cheong Moon Gak Publishing Co. (1983).

- PIGANIOL, P.: Les industries verrières. Edit. Dunod (1966).

- RAWSON, H.: Properties and applications of glass. Elsevier (1980).

- Diversos estudios e informes internos de los Centros de Investigación: CIDA: Cristaleria Española, S.A. Aviles.

SGR: Saint Gobain Recherche. París.

ZAF: Vereinigte Glaswerke GmbH. Aachen. 